Discussion Paper No. 07-070

\title{
The Phillips Curve and
} NAIRU Revisited:

\section{New Estimates for Germany}

Bernd Fitzenberger, Wolfgang Franz, and Oliver Bode

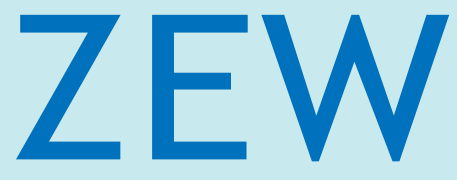

Zentrum für Europäische Wirtschaftsforschung $\mathrm{GmbH}$

Centre for European

Economic Research 
Discussion Paper No. 07-070

\title{
The Phillips Curve and NAIRU Revisited: \\ New Estimates for Germany
}

\author{
Bernd Fitzenberger, Wolfgang Franz, and Oliver Bode
}

Download this ZEW Discussion Paper from our ftp server:

ftp://ftp.zew.de/pub/zew-docs/dp/dp07070.pdf

Die Discussion Papers dienen einer möglichst schnellen Verbreitung von neueren Forschungsarbeiten des ZEW. Die Beiträge liegen in alleiniger Verantwortung

der Autoren und stellen nicht notwendigerweise die Meinung des ZEW dar.

Discussion Papers are intended to make results of ZEW research promptly available to other economists in order to encourage discussion and suggestions for revisions. The authors are solely responsible for the contents which do not necessarily represent the opinion of the ZEW. 


\section{Non-Technical Summary}

The "non-accelerating inflation rate of unemployment" (NAIRU) indicates a threshold figure: If the actually observed unemployment rate exceeds the NAIRU, existing unemployment may decline without facing higher inflation rates. Once the NAIRU threshold is attained, however, the situation is different. As long as inflation rates are to be kept stable, a further reduction of unemployment can be achieved only by supply side measures such as a higher flexibility of the labor market or more moderate wage increases. Hence, the NAIRU represents a rough borderline between a "deficiency-of-demand" component of unemployment and a "structural" part no matter what is meant by the latter term in concreteness.

This paper provides new econometric estimates of a time-varying NAIRU for Germany. Several econometric methods such as the Kalman filter and the partially linear model are employed and confidence intervals are calculated. While the Phillips curve serves as a theoretical starting point, this framework is extended in order to test for hysteresis and near rationality.

As an empirical result for the year 2006, the NAIRU for Germany amounts to 7 percent using the ILO concept of measuring unemployment or 9 percent if the concept of registered unemployment is employed. Since the early 1990's the NAIRU has remained fairly stable but may decline in the following years due to the labor market reforms and pursued moderate wage policy. 


\title{
The Phillips Curve and NAIRU Revisited: New estimates for Germany ${ }^{1}$
}

\author{
Bernd Fitzenberger ${ }^{2}$, Wolfgang Franz ${ }^{3}$ and Oliver Bode ${ }^{4}$
}

August 2007

\begin{abstract}
This paper provides new estimates of a time-varying NAIRU for Germany taking account of the structural break caused by German unification based on the Kalman Filter and on a partially linear model as two alternatives. Estimating a standard Phillips curve, the sum of coefficients associated with expected inflation is far beyond unity, whatever measure of expected inflation rates is employed. Therefore, either the NAIRU concept is not applicable to Germany or, as it is our suggestion, one estimates the unemployment rate that is compatible with a tolerable inflation rate of say 2 percent following roughly the inflation target put forward by the European Central Bank. The estimates presented in this paper suggest that the NAIRU compatible with 2 percent inflation in Germany is currently around 7 percent if the definition of unemployment follows the concept of the ILO. In contrast to the consensus in the literature, our estimates suggest furthermore that the NAIRU in Germany has not increased since the early 1990's.
\end{abstract}

JEL classification: C22, E24, E31.

Keywords: NAIRU, unemployment, inflation, Phillips curve, Okun's Law, German unification, Kalman Filter, partially linear model.

\footnotetext{
${ }^{1}$ Paper presented at the conference "The Phillips Curve and the Natural Rate of Unemployment" at Kiel, June 3-4, 2007. We thank the conference participants for helpful comments. All errors are our sole responsibility.

${ }^{2}$ University of Freiburg and Center for European Economic Research (ZEW), Mannheim.

${ }^{3}$ Center for European Economic Research (ZEW), Mannheim, University of Mannheim, and German Council of Economic Experts.

${ }^{4}$ German Council of Economic Experts. The views expressed in this paper are those of the authors and they do not necessarily reflect the views of the Council of Economic Experts.
} 


\section{Introduction and Motivation}

Starting in 2006 the German economy currently experiences a cyclical revival which spreads to the labor market. Unemployment decreases markedly and regular employment rises. Against this background a debate has taken center stage as to what extent unemployment figures consist of merely cyclical components or, in other words, which part of joblessness can be labeled as "structural". "Structural" unemployment, however, is a loaded word since there is no clear cut consensus about its meaning, let alone its measurement. Hence, the question arises whether the "non-accelerating inflation rate of unemployment" (NAIRU) may serve as a tool to determine the development and current level of non-cyclical unemployment and to frame policy discussions.

At first glance, the NAIRU appears as a promising candidate for an empirical counterpart of the "natural rate of unemployment". Moreover, its estimation seems straightforward by employing more or less conventional Phillips curves. But as the rich literature of the past four decades already suggests, this view is exaggerated. By any method, simple or complex, the NAIRU is very hard to determine. As to the simple method, an inspection of a scatter diagram of inflation and unemployment displays that there is no such thing like a stable Phillips curve. A more complex method is to estimate Phillips curves preferably with time-varying parameters and confidence intervals for the estimated NAIRU. However, this procedure suffers from serious problems making the NAIRU subject to considerable arbitrariness, to say the least. Even worse, the whole NAIRU idea may be seriously damaged if the joint behavior of inflation, wage rises and unemployment has deteriorated.

Rather than to embark on a swan song on the NAIRU, in this paper we try to remedy some of the flaws which plagued previous NAIRU estimates for Germany. More precisely, we employ direct measures of inflation expectations stemming from the EC monthly survey and converted from qualitative responses to quantitative estimates of expected inflation rates. Second, we deal with the question of near-rationality during periods of low inflation. Third, we provide state-of-the-art time-varying NAIRU estimates together with confidence intervals. The upshot of our paper will be an assessment of the NAIRU in Germany.

Recently, there has been a strong interest in estimating how the NAIRU changes over time. ${ }^{5}$ There has been a strong interest in estimating a time-varying NAIRU for some European countries or for the Euro-Area as a whole. ${ }^{6}$ The literature often applies a Kalman-Filter approach and estimates the time-varying NAIRU as an unobserved state variable. In doing so, various methodological issues have to be resolved ${ }^{7}$ which we address in section 5 of this paper. We estimate a Kalman-Filter model for Germany allowing for a structural break due to German Unification in the third quarter of 1990. Since the Kalman-Filter estimates do not always converge we estimate a partially linear model (Robinson, 1988) with a nonparametric component in time as a simple robust alternative. Our data are for West Germany before unification and for united Germany

\footnotetext{
${ }^{5}$ The seminal papers by Gordon $(1997,1998,2006)$ and Staiger et al. (1997a,b) estimate a timevarying NAIRU for the US.

${ }^{6}$ See among others Laubach (2001), Fabiani and Mestre (2001), Franz (2005), Logeay and Tober (2006, 2007), and Schumacher (2007).

${ }^{7}$ See e.g. Laubach (2001) or Schumacher (2007).
} 
after unification. We address the issue that a NAIRU in the literal sense of the word does not exist for Germany because in the inflation equation our proxies for expected inflation always show a coefficient which is significantly smaller than one. In light of this result, we estimate the NAIRU as the unemployment rate which is compatible with a tolerable inflation rate of $2 \%$ (Franz, 2005). We also investigate whether joint estimation of an inflation equation and Okun's law for Germany helps to estimate the NAIRU in a better way.

There seems to be a consensus in the literature that the NAIRU in the Euro-zone and in Germany increased both in the 1980's and the 1990's. Our results support this concensus for the 1980's but not for the 1990's. The Kalman-Filter estimates show a slight U-shaped pattern of the NAIRU between 1990 and 2006. However, the time trend is not significant and our preferred estimates show a constant NAIRU since 1990.

The remainder of this paper is organized as follows. The next section highlights shortly the development of major macroeconomic variables in Germany, notably inflation rates and unemployment rates. Section 3 provides an extremely brief outline of the theoretical framework of traditional and extended versions of the NAIRU. Section 4 discusses specification issues, such as the calculation of expected inflation rates. Section 5 is devoted to attempts to test for near-rationality and (Hybrid) New Keynesian Phillips curves. Finally, section 6 concludes.

\section{The Behaviour of Inflation and Unemployment in Germany}

As a prerequisite of the following considerations the empirical picture of the Phillips curve and the NAIRU is highlighted by the following figures. Figures 1 and 2 display the conventional scatter diagrams for the Phillips curve with the inflation rate of consumer prices and the rate of change of the GDP deflator as the dependent variables, respectively. As can be seen whatever measure

Figures 1 and 2 around here

of inflation is used the German Phillips curve, if it exists at all, is anything but a stable (vertical) relationship. The evidence for the NAIRU is presented by figures 3 and 4 where inflation rates are replaced by their first differences. The NAIRU is then given by

Figures 3 and 4 around here

the horizontal line for a value of zero of these differences. Again, there is no such thing as a unique value of the NAIRU, if there is a NAIRU at all. If so, the NAIRU has increased substantially over the past decades and amounts to roughly (8) percent in most recent years. 


\section{Theoretical Framework: Basics and Extensions}

The theoretical underpinnings of the NAIRU concept are well documented in the literature. ${ }^{8}$ Hence, it may suffice here to very briefly sketch an outline of its framework. The basic specification of the NAIRU refers to a descriptive reduced form of a price and wage equation such as:

$$
p_{t}=a(L) p_{t-1}-b(L)\left(U_{t}-U^{*}\right)+c(L) z_{t}+\varepsilon_{t} .
$$

In this notation lower-case letters designate first differences of logarithms. Hence, $p_{t}$ and $p_{t-1}$ represent current and lagged inflation rates, respectively, and $z_{t}$ is a vector including rates of changes of supply shift variables such as raw material prices and tax wedges. Upper-case letters indicate levels of variables, hence, $U_{t}$ and $U^{*}$ denote the current unemployment rate and a constant natural rate, respectively. The coefficients $a(L), b(L)$ and $c(L)$ are polynomials in the lag operator $L$, and $\varepsilon$ is a serially uncorrelated error term. Equation (1) incorporates informally Gordon's (1997) "triangle model" of the NAIRU: Influences stem from the demand side (via $U_{t}-U^{*}$ ), the supply side (via $z_{t}$ ), and from price rigidities (via $a(L) p_{t-1}$ ) and, perhaps even more important, from expected inflation (approximated by adaptive expectations, i.e., a distributed lag of observed inflation rates) which has taken center stage ever since the seminal Friedman-Phelps-hypothesis of the late 1960's. Note further that the supply shocks are assumed to be contemporaneously uncorrelated with unemployment.

If $a(1)=1$ the NAIRU can be calculated from equation (1) for stable inflation rates: ${ }^{9}$

$$
\mathrm{NAIRU}=U^{*}+c(1) z_{t} / b(1) .
$$

In the absence of supply shocks (i.e., for $z=0$ ), the NAIRU equals $U^{*}$. For this case, an estimate of $U^{*}$ can be calculated from the intercept $d \equiv b(1) U^{*}$ of the following regression equation:

$$
p_{t}=d+a(L) p_{t-1}-b(L) U_{t}+\varepsilon_{t} .
$$

$U^{*}$ is referred to as the "no shock-NAIRU" (Franz and Gordon (1993)). It stands in contrast to a NAIRU concept which takes into account the presence of shocks $z \neq 0$. No matter of the specific nature of these exogenous shocks, they give rise to a crucial distinction between a "shock-NAIRU" and a "no shock-NAIRU" depending on whether inflationary effects stemming from these shocks should be ironed out by higher unemployment. For example, proponents of a no shock-concept would argue that the resulting transitory increase of inflation - such as in the case of higher indirect taxes should be disregarded.

\footnotetext{
${ }^{8}$ See e.g. Franz and Gordon (1993) and Franz (2005).

${ }^{9}$ Hence, the term NAIRU - an acronym anyway - is misleading due to a false use of calculus: The absence of a change of inflation is confused with "non-accelerating inflation", i.e. the first order of differentiation of inflation is confused with the second order.
} 
Allowing for a time varying-NAIRU, $U^{*}$ is replaced by $U_{t}^{*}$ with the latter being described by a random walk without drift, for example:

$$
U_{t}^{*}=U_{t-1}^{*}+\eta_{t}
$$

with $E\left(\eta_{t}\right)=0$ and $\operatorname{var}\left(\eta_{t}\right)=\sigma^{2}$. For $\sigma=0$ we obtain the constant NAIRU, whereas for $\sigma>0$ the NAIRU is subject to fluctuations. Such fluctuations can be the result of changing explanatory variables not included in equation (1). A time varying-NAIRU can also be driven from hysteresis phenomena such as a dequalification and disencouragement of (long-term) unemployed persons.

Referring to hysteresis and to equation (4), the development of $U_{t}^{*}$ can be described more precisely by

$$
\begin{gathered}
U_{t}^{*}=\bar{U}+\phi\left(U_{t-1}-\bar{U}\right)+\mu_{t} \\
\mu_{t} \sim N\left(0, \sigma_{\mu_{t}}^{2}\right) .
\end{gathered}
$$

In words, $U_{t}^{*}$ is now a "contemporaneous NAIRU", because of its time dependency, whereas $\bar{U}$ is the "steady state-NAIRU" or "equilibrium-NAIRU". Inserting equation (5) into equation (1) and rearranging terms yields ( $\Delta$ denotes the first difference operator):

$$
\begin{gathered}
p_{t}=a(L) p_{t-1}-b(L)\left[(1-\phi)\left(U_{t}-\bar{U}\right)+\phi \Delta U_{t}\right] \\
+c(L) z_{t}+\varepsilon_{t}+b(L) \mu_{t} .
\end{gathered}
$$

Three cases are of interest: ${ }^{10}$

(i) Full hysteresis: If $\phi=1$, then the "level effect" vanishes and there is no such thing like a unique NAIRU.

(ii) No hysteresis: If $\phi=0$, then the change term $\Delta U_{t}$ drops out and the pure Phillips curve mechanism works.

(iii) Persistence: If $0<\phi<1$, both the level and change effect of $U_{t}$ matter and the contemporaneous NAIRU can drift away from the steady state-NAIRU.

This distinction is not an artifact of the specification of the time path in equation (6) but holds for more generalized versions, too. ${ }^{11}$ More importantly, the consequences of hysteresis or persistence for the NAIRU are tremendous. A high level of unemployment today means a higher NAIRU tomorrow, or conversely, fighting successfully against unemployment today will partly avoid problems tomorrow. In methodological terms,

\footnotetext{
${ }^{10}$ See also Franz (1987) and Franz and Gordon (1993).

${ }^{11}$ See Franz (2001), eqs. (13) and (14).
} 
in the presence of hysteresis or persistence there is a considerable risk of overestimating the NAIRU due to confusing the contemporaneous with the steady-state NAIRU.

A negatively sloped Phillips curve, if it exists, is of special interest because the traditional NAIRU concept breaks down. In the case $a<1$, inflation rates do not cancel out in equilibrium (i.e., for stable inflation rates) as it is required by the NAIRU concept.

The rationale for $a(1)=1$, i.e. the implication of a long-run vertical Phillips curve is based on the Friedman-Phelps-hypothesis of the late 1960's which claims that workers care about and bargain for real wage increases rather than nominal wage gains. Based on this reasoning it was concluded that the coefficient associated with expected inflation - the latter being represented, as in equation (1), by lagged inflation rates - must be one.

There are two different although not mutually exclusive arguments of why this restriction may not necessarily hold. The first one can be traced back to Sargent (1971) who pointed out that the coefficient on lagged inflation may not be unity even in an accelerationist model of inflation as long as the process of generating inflation is stable (without a unit root). A sum of weights of past inflation rates less than unity must not necessarily reflect incomplete projection of inflation but rather the view that inflation is stationary and its best forecast is an autoregressive process with a stable polynomial, not one where the coefficients sum to one. ${ }^{12}$

A second argument of why the controversial number in the Phillips curve may fall short of unity has been brought forward by Akerlof et al. (2000). The authors refer to "behavioral macroeconomics" and present two hypotheses on why at low inflation there may be a long-run trade-off between output and inflation. The first one is "pure Keynes": workers resist, and firms rarely impose, cuts in nominal pay. Both, low inflation and nominal wage rigidity, then form a major obstacle against a downward adjustment of real wages. ${ }^{13}$ On the other hand, there may be a possible benefit of low inflation serving as a lubricant of labor market adjustment. ${ }^{14}$ With a little more inflation real wages can adjust (more rapidly) and aggregate unemployment falls. The other argument put forward by Akerlof et al. (2000) is based on the idea that because inflation is not salient when it is low, anticipated future changes in the price level are ignored in wage bargaining. Put differently, the crucial parameter under consideration in the Phillips curve represents a combined effect of how people form expectations and how they use them. At higher inflation, wage bargaining takes expected inflation into account and the Phillips curve may become vertical indeed. At low inflation, workers are (voluntarily) fooled, there is a negatively sloped Phillips curve.

While Akerlof et al. (2000) elaborate on a fairly sophisticated theory, the upshot of their hypothesis is that the coefficient in question depends on past inflation experience. This is a testable hypothesis. There are at least two groups of econometric methods which may be considered. The first is to let the data speak, i.e., to estimate the Phillips curve with a time-varying parameter (at least) of the co-

\footnotetext{
${ }^{12}$ See also Schreiber and Wolters (2007).

${ }^{13}$ See also Graham and Snower (2002) and Snower and Karanassou (2002). In their papers they show that the interaction between money growth and staggered nominal contracts may give rise to a long-run inflation-unemployment tradeoff.

${ }^{14}$ For an empirical study for Germany see Franz (1984).
} 
efficient associated with lagged inflation by, for example, splitting the sample period between low inflation periods and high inflation periods. The second group is based on theoretical considerations and, following Akerlof et al. (2000), decomposes the coefficient associated with lagged inflation $a$ in two separate influences, i.e., $a \equiv 1-(1-\alpha)(1-\beta)$, where $(1-\alpha)$ denotes the fraction of all firms which ignore a fraction $(1-\beta)$ of expected inflation. Hence, if $\alpha=\beta=1$ we are back to the vertical Phillips curve. But with half a fraction of firms which ignore half of expected inflation, the coefficient $a$ amounts to 0.75 , or to 0.56 if "half" is replaced by "two thirds". Moreover, the coefficient $a$ has to be constrained to range between zero and one by, say, using a standard cumulative normal distribution.

The mainstream model presented so far has been challenged by the "New Keynesian Phillips Curve" (NKPC) and the "Hybrid New Keynesian Phillips Curve" (HNKPC), respectively. Both concepts are subject to disagreement: They are "the workhorse for much recent research on monetary policy" (Mankiw (2001)) on the one hand or "the NKPC enterprise has resulted in a massive empirical failure, perhaps with few parallels in postwar empirical time-series macroeconomics" (Eller and Gordon (2003)) on the other hand. In what follows we highlight major differences compared with the mainstream model.

\section{Specification Issues}

This section is devoted to econometric issues and data analysis. Subsection 4.1 discusses firstly cointegration issues. Subsection 4.2 deals with various definitions of inflation and unemployment and, moreover, elaborates on the calculation of expected inflation rates. Finally, subsection 4.3 discusses direct measures of inflation expectations used in this paper.

\subsection{Cointegration Issues}

Conventional Phillips curve estimates in the spirit of equation (2) are subject to the criticism of a possible serious misspecification stemming from omitted considerations about cointegration issues. ${ }^{15}$ More precisely, when inflation and unemployment are cointegrated, i.e., the linear combination of their time series is stationary, a regression consisting entirely of differenced data will be misspecified and a regression consisting entirely of undifferenced data will omit important constraints. ${ }^{16}$

To begin with, an elaboration on this issue requires firstly an inspection of the order of integration of the time series under consideration. ${ }^{17}$ If inflation is stationary, then no vertical Phillips curve can exist; but there may be a short-run one. If inflation is I(1), the NAIRU conception may hold depending on whether unemployment is I(1). If inflation is $\mathrm{I}(1)$ and unemployment is also $\mathrm{I}(1)$, the outcome depends on whether

\footnotetext{
${ }^{15}$ See e.g. Schreiber and Wolters (2007).

${ }^{16}$ See Franz and Gordon (1993), p. 730.

${ }^{17}$ See Schreiber and Wolters (2007) for the following different cases.
} 
cointegration exists between both variables. If so, then a long-run Phillips curve may exist. If not, there is no long-run Phillips curve, but there may be a short-run relationship and filtering out the persistent component of unemployment (which is unrelated to inflation) has some merits.

While these methodological considerations deserve attention, one should resist the temptation to place too much emphasis on them. The Phillips curve is not simply a relationship between inflation and unemployment but is augmented by several variables. Besides this, other variables, not included in the Phillips curve framework but important, may govern variables such as inflation which is influenced by the development of monetary aggregates. Similar arguments hold for unemployment. If so, the Phillips curve can be consistent with a variety of orders of integration which puts the above considerations into question. ${ }^{18}$ Moreover and strictly speaking, the unemployment rate cannot be I(1) since it is a bounded variable. However, it is often claimed that this property serves "as a useful approximation to reality within the bounds" (Schreiber and Wolters (2007)). For all practical purposes, I(1) is what ADF-tests display for the unemployment rate in (West) Germany. Even so, some scepticism remains about the appropriateness of such generalizations. If we stay with an unemployment rate of order I(1) nevertheless, the next relevant question is whether inflation has an order of integration of at least I(1). Again, I(1) is what ADF tests for Germany typically reveal (despite the high reputation of the Deutsche Bundesbank). ${ }^{19}$ Hence, a test for cointegration is in order. This can be carried out by the Johansen procedure as has been done by Schreiber and Wolters (2007) or as in Franz (2003) by a residual-based cointegration test where the residuals from the static Phillips curve regression are taken in a second step to carry out an ADF-type regression testing for a unit root in the residuals. In the presence of a unit root (this is the null hypothesis), i.e., in the absence of stationarity, absence of cointegration cannot be rejected. Lack of space prohibits to present all the results and the reader is referred to subsection 5.1 and, moreover, to Schreiber and Wolters (2007) or Franz (2003). In short, the results are rather mixed but cointegration cannot be rejected.

\subsection{Measures of Inflation and Unemployment Rates}

Even the most simple version of a Phillips curve requires reflections on how to measure important variables such as inflation and unemployment. In addition, data problems stemming from German unification and revisions of national accounts and employment statistics, respectively, have to be taken into account. As will be shown below, the NAIRU estimates are very sensitive to the definition under consideration.

Starting with inflation, both the use of consumer prices as well as the GDP deflator can be justified on theoretical grounds. This holds for the Phillips curve derived either from a non-structural approach, e.g. a reduced form of wage and price equations, or from a structural approach based on explicit models of labor demand and labor supply, respectively. ${ }^{20}$ For example, in a wage equation which reflects outcomes of wage

\footnotetext{
${ }^{18}$ To some extent, however, $U_{t}^{*}$ may capture non-stationarity.

${ }^{19}$ See also our results on unit root tests in section 5.1 .

${ }^{20}$ See Franz and Gordon (1993) for both approaches.
} 
bargaining, employers base their considerations on product wages, but employees on consumption wages. Product wages include employers' taxes on labor and contributions to social security and are deflated by sales prices, or, for the aggregate economy, by the GDP deflator for the private, non-agricultural sector (because prices in the governmental and agricultural sector are strongly regulated and, moreover, subject to somewhat erratic fluctuations). On the other hand, for employees and the unions the variable of interest in wage bargaining is the consumption wage, i.e., gross wages net of taxes and contributions to social security to be paid by employees and deflated by prices which represent costs of employees' living. Therefore, the estimations of the Phillips curve in the subsequent section will be based on both, the inflation rate of consumer prices as well as on the rate of change of the private, non-agricultural GDP deflator. In addition, whatever definition of inflation is used, we test the significance of a price and tax wedge variable, respectively. These variables have already been introduced in the vector $z$ in equation (1) as "supply shift variables" which can alter the rate of inflation at a given level of excess demand. By the same token, relative imported raw materials prices also constitute a supply shock as is evidenced by the two oil price shocks in 1974 and 1982. The variable which will be used in the regressions below is the inflation rate of raw materials prices minus the inflation rate which corresponds with the dependent variable. Table 1 displays a summary statistic of these and other variables under consideration.

Unemployment is the second variable under consideration. Recall from the theoretical model that it is designed to capture the pressure stemming from the labor market in wage bargaining and, on the other hand, the respective situation on the product market in the price-setting process. Indeed, the whole NAIRU idea is that unemployment is a good measure of pressure in labor markets. Moreover, if the mechanism of tight labor markets causing rising wages will turn out not to be central to the inflation process, the NAIRU framework is seriously damaged. While the unemployment rate in the wage equation may properly capture excess supply on the labor market, it is doubtful whether this holds for a situation of excess labor demand which may be more adequately measured by vacancies. Moreover, the tightness of the product market may be better represented by the capacity utilization rate or detrended output rather than by the unemployment rate. Of course, unemployment and capacity utilization may be (closely) connected via Okun's law but empirical investigations of the Okun curve (as well as of the Beveridge curve which relates unemployment with vacancies) reveal somewhat unstable relationships, to say the least. ${ }^{21}$ For this reason, Franz and Gordon (1993) elaborated on a German "Mean-Utilization Rate of Unemployment" (MURU), i.e., the unemployment rate consistent with an average mean utilization rate (of 84.4 per cent of potential output during the time period 1962 to 1990). Obviously, to explain the sense of a MURU to policy makers and to the public is an even more demanding if not unsurmountable obstacle compared with the NAIRU. ${ }^{22}$

\footnotetext{
${ }^{21}$ See Franz (1987) and Franz and Siebeck (1991).

${ }^{22}$ Moreover, experiments with estimated output gaps in the Phillips curve did not yield a substantial higher explanatory power. See Franz (2001).
} 
Table 1: Summary measures of inflation rates, unemployment rates and wedge variables $^{a}$ )

\begin{tabular}{|c|c|c|c|c|c|c|c|c|c|}
\hline $\begin{array}{l}\text { Average } \\
\text { over } \\
\text { interval }\end{array}$ & \multicolumn{2}{|c|}{$\begin{array}{l}\text { Inflation } \\
\text { rates p.a. }\end{array}$} & \multicolumn{2}{|c|}{$\begin{array}{l}\text { Inflation rates } \\
\text { of relative raw } \\
\text { material prices }\end{array}$} & $\begin{array}{c}\text { Tax } \\
\text { wedge }\end{array}$ & $\begin{array}{l}\text { Price } \\
\text { wedge }\end{array}$ & $\begin{array}{l}\text { Labor } \\
\text { produc- } \\
\text { tivity } \\
\text { growth }\end{array}$ & \multicolumn{2}{|c|}{$\begin{array}{l}\text { Unemploy- } \\
\text { ment rates }\end{array}$} \\
\hline & $(1)$ & (2) & $(3)$ & (4) & (5) & (6) & (7) & $(8)$ & (9) \\
\hline $1971-1975$ & 6.07 & 6.14 & & & 1.58 & 0.92 & 4.65 & 1.83 & 1.09 \\
\hline $1976-1980$ & 3.94 & 4.04 & $8.62^{b}$ & $8.73^{b}$ & 1.68 & 0.94 & 2.70 & 3.59 & 2.03 \\
\hline $1981-1985$ & 3.33 & 3.85 & 2.11 & 1.59 & 1.74 & 0.95 & 2.18 & 7.22 & 5.40 \\
\hline $1986-1990$ & 2.38 & 1.38 & -13.86 & -12.85 & 1.77 & 0.92 & 2.88 & 7.34 & 5.45 \\
\hline $1991-1995$ & 2.95 & 3.69 & -9.21 & -9.95 & 1.81 & 0.94 & 2.57 & 8.25 & 6.39 \\
\hline $1996-2000$ & 0.10 & 1.26 & 9.53 & 8.37 & 1.94 & 0.98 & 2.03 & 10.61 & 7.76 \\
\hline $2001-2006$ & 0.91 & 1.62 & 8.46 & 7.74 & 1.90 & 1.02 & 1.43 & 10.45 & 8.28 \\
\hline
\end{tabular}

a: Notes by column number in parentheses. Numbered sources in brackets identified at the end of notes. Inflation rates in cols. (1) - (4) and (7) are calculated as geometric means of annual growth rates.

b: Results for the period from 1977 to 1980 .

Columns: (1) Rate of change of GDP deflator of the private non-farm sector [1].

(2) Rate of change of consumer price index [1].

(3) Difference between rate of change of prices of imported raw materials and rate of change of GDP deflator of the private non-farm sector [1].

(4) Difference between rate of change of prices of imported raw materials and rate of change of consumer price index [1].

(5) Ratio of employer labor cost (including employers' contributions to social security) to employee net take home pay (excl. employees' taxes on labor and contributions to social security) $(2000=100)$, [1].

(6) Ratio of consumer price index to GDP deflator of private non-farm sector $(2000=100),[1]$.

(7) Rate of change of labor productivity on an hourly basis, [1].

(8) Unemployment rate according to definition by the German Federal Labor Office [2].

(9) Unemployment rate according to definition by the International Labor Office [1].

Sources: [1] Statistisches Bundesamt.

[2] Bundesagentur für Arbeit

\subsection{Inflation Expectations}

The use of distributed lags of actual inflation rates as a proxy for inflation expectations implies testing a combined hypothesis, namely to what extent inflation expectations contribute to an explanation of actual inflation rates, as claimed by the Phillips curve, and whether the proxy for inflation expectation corresponds with true expectations by the economic agents under consideration. Hence, the need for direct measures of 
inflation expectations is obvious but to meet this requirement is not. ${ }^{23}$

Basically, two types of direct measures of inflation expectations are available for Germany albeit for a limited time period. The first is the EC monthly survey and rests on asking consumers about their expectations for consumer prices, the second is published by the Center for European Economic Research (ZEW) and relies on a survey among professional forecasters. Both approaches have their merits and problems. At first glance, asking consumers directly seems to provide exactly the information desired. However, in the absence of a strong motivation of respondents to answer correctly, the reliability of those data may be questioned even if the sample is large. ${ }^{24}$ On the other hand, professional forecasters may handle the survey questions more seriously. But it is unclear whether their replies are unbiased at any point of time given potential strategic interests. Most importantly, however, these data are available only since December 1991. ${ }^{25}$ Therefore we employ the EC monthly survey which starts in 1985.

The EC survey is not designed to give precise quantitative forecasts of inflation but rather is a tendency survey in which the respondents may choose among six categories of responses. The monthly survey for Germany poses the following question ("Question 6") to approximately 2500 consumers: "By comparison with the past 12 months, how do you expect that consumer prices will develop in the next 12 months? They will ... (1) increase more rapidly, (2) increase at the same rate, (3) increase at a slower rate, (4) stay about the same, (5) fall or (6) don't know." Available time series of the shares of respondents replying to each category start in 1985. An argument in favor of gathering qualitative rather than quantitative data is that consumers are more likely to have an opinion on the direction of future price changes than to give exact forecasts of inflation for a certain period of time.

In this paper quantitative estimates of the expected rates of inflation from these qualitative data are obtained by using a modified Carlson and Parkin-methodology as it is carried out by Gerberding (2001). In short, the central idea behind the approach by Carlson and Parkin (1975) is to interpret the share of consumers replying to each category $^{26}$ as maximum likelihood estimates of areas under the density function of aggregate inflation expectations. ${ }^{27}$ The expected value of that density function represents the average inflation rate expected by survey respondents. However, the calculation of the inflation expectations is complicated by the fact that consumer assessments of expected prices in the next 12 months are linked to their perception of price developments during the past year. Therefore the mean expected inflation rate is the product of the mean assessment of price developments in the last 12 months and a factor calculated using the density function above - which reflects the change in the evalua-

\footnotetext{
${ }^{23}$ See the studies by Akerlof et al. (2000) for the U.S. and by Driver et al. (2003) for the U.K. and the U.S.

${ }^{24}$ Note that accuracy of the forecasts is not the issue here as long as economic agents behave on the basis of their (false) forecasts.

${ }^{25}$ See the ZEW-Finanzmarktreport (monthly, in German) and the ZEW-news (quarterly, in English) for more information. Inflation expectations are published as the results of the ZEW Financial Market Test (ZEW Finanzmarkttest), see the ZEW homepage at www.zew.de.

${ }^{26} \mathrm{As}$ is common practice, the responses in the category "Don't know" are distributed proportionally among the other categories.

${ }^{27}$ The density function is assumed to be a standard normal. See also Gerberding (2001), Batchelor and Orr (1988) and Reckwerth (1997).
} 
tion of future inflation rates relative to past inflation rates. Gerberding $(2007,2001)$ assumes that respondents correctly perceive the actual rate of inflation at the time they form their expectations. While this assumption is not as innocuous as it may seem, given the misperceptions of inflation rates by consumers at least in Germany in due course of the introduction of the Euro, it seems plausible in other time periods of low inflation. ${ }^{28}$ Another solution would be the use of the following question of the EC survey, where respondents are asked to condition their replies on their perceptions of current inflation. The exact wording of this question ("Question 5") is as follows: "How do you think that consumer prices have developed over the last 12 months? They have ... (1) risen a lot, (2) risen moderately, (3) risen slightly, (4) stayed about the same, (5) fallen or (6) don't know." Quantification of inflation expectations is in this case however complicated by the fact that one needs additional information what consumers consider as a "moderate" rate of inflation.

For the period from 1985 to 2006 - except for the years 1991 to 1993 - inflation rates stay in a narrow range between 0 and 3 per cent, i.e. the volatility of price developments in Germany is overall low. A look at the inflation expectations (for the next 12 months) reveals for the period under observation only small differences to the actual inflation rate at the time the respondents form these expectations. This is especially true for the inflation expectations based on the assumption that consumers correctly perceive the actual inflation rate. Among other things this is caused by the fact that for the period under consideration on average more than half of the respondents (about 52 per cent) reply to category (2) ("prices will increase at the same rate") of "Question 6 ", that means on average more than half of the consumers expect constant inflation rates. This indicates that the expectations of households are strongly guided by current (and past) price developments. The picture changes only slightly when "Question 5" is additionally considered to calculate inflation expectations, which means giving up the assumption that consumers correctly perceive the actual inflation rate.

\section{Econometric Approach}

Our empirical goal is to estimate the time-varying NAIRU (TV-NAIRU, for short) for Germany taking account of the structural break induced by German unification. In our empirical analysis, we will use quarterly data for West Germany for the time period 1976:2 to 1990:2 and quarterly data for unified Germany for the time period 1990:3 to 2006:4. All estimated models involve a post unification dummy variable to capture a level shift of German unification, irrespective of whether the coefficient is significant.

The literature on estimating a TV-NAIRU typically uses state space models to capture the dynamics of the NAIRU over time. ${ }^{29}$ The evoluation of the NAIRU over time is modelled by a separate equation for an unobserved state and it is extracted from the data using the Kalman filter. Studies differ to what extent the structural parameters of the state equation are estimated based on the data and as to whether they report

\footnotetext{
${ }^{28}$ See Forsells and Kenny (2002) for other approaches covering the Euro Area.

${ }^{29}$ See Gordon $(1997,1998,2006)$ and Staiger et al. (1997a,b) for the seminal contributions. Among many others, Laubach (2001), Fabiani and Mestre (2001), Franz (2005), Logeay and Tober (2006, 2007), and Schumacher (2007) involve applications of this concept to European data.
} 
confidence bands around the estimated NAIRU. The literature providing KalmanFilter estimates of the TV-NAIRU for the Euro-zone or for Germany ignores the structural break caused by Germany unification.

Estimation of the structural parameters of a state space model can be difficult (and is impossible in a number of cases of interest in this paper). Confidence intervals of the estimated TV-NAIRU tend to be large thus questioning the usefulness of the NAIRU concept. ${ }^{30}$ In addition, the so-called pile-up problem arises from the fact that the likelihood function can have point mass at zero for the variance of the change of a nonstationary state variable, even if the true value is greater than zero. ${ }^{31}$ It is often suggested in the literature, ${ }^{32}$ that more precise estimation is feasible by adding equations to the state-space system of estimated equations. In addition to the inflation equation, studies add a stationary model in the unemployment gap ( $\equiv U_{t}-U_{t}^{*}$, i.e. difference between actual unemployment rate and TV-NAIRU) or a dynamic version of Okun's law. ${ }^{33}$

Because of the severe practical estimation problems involved, we suggest a second, more robust semiparametric estimator for a TV-NAIRU based on the semiparametric estimator of the partially linear model introduced by Robinson (1988). This estimator involves a smooth kernel regression in time which, after appropriate transformation, describes the evolution of the TV-NAIRU. While this semiparametric estimator provides a robust estimate for all cases considered in this paper, the estimation of structural parameters of a state space model proves infeasible in some cases.

In the following, we first discuss the results of unit root tests for the unemployment rate and for cpi inflation. These tests are important for the specification of the estimated state space models. Then, we describe the details of the two estimation approaches taken in this paper.

\section{$5.1 \quad$ Unit Root Tests}

Table 2 reports the results of unit root tests for the unemployment rate and for cpi inflation. The results for the level of the unemployment rate suggests that the null of a unit root can not be rejected. The same test for the change in the unemployment rate can be decisively rejected at a significance level of 5 percent. Thus, in accordance with previous evidence (Schreiber and Wolters, 2007, or Franz, 2003), $U_{t}$ seems an I(1) variable. We conclude that it would be inappropriate to specify the TV-NAIRU as an $\mathrm{I}(2)$ variable because the unemployment rate is an $\mathrm{I}(1)$ variable. This is partly in contrast to Laubach (2001), Fabiani and Mestre (2001), and Schumacher (2007), who

\footnotetext{
${ }^{30}$ See Staiger et al., 1997a,b.

${ }^{31}$ See Staiger et al. (1997a,b), Stock and Watson (1998) and Laubach (2001). Stock and Watson (1998) develop a median unbiased estimator of this variance, which is not used in this paper. When we obtain a variance estimate close to zero for our application, we will see that it is typically plausible that the true variance is very small or even exactly zero. In some cases, however, we have the opposite problem, namely, we obtain variance estimates which tend to infinity and which yield incredible variations in the TV-NAIRU, see below.

${ }^{32}$ See e.g. by Laubach, 2001, and Schumacher, 2007.

${ }^{33}$ See Laubach (2001), Fabiani and Mestre (2004) and Schumacher (2004).
} 
estimate the TV-NAIRU as an I(2) variable. We specify the TV-NAIRU as an I(1) variable.

Table 2: Unit Root Test Results

\begin{tabular}{lrrr}
\hline & \multicolumn{3}{c}{ Variable } \\
Test & $U_{t}^{b}$ & $\Delta U_{t}^{b}$ & $p_{t}{ }^{c}$ \\
\hline Augmented Weighted Symmetric $\tau$ & 0.2040 & 0.0000 & 0.0080 \\
Augmented Dickey-Fuller & 0.2760 & 0.0350 & 0.3850 \\
Phillips-Perron & 0.4010 & 0.0000 & 0.0000 \\
\hline
\end{tabular}

a: P-Values when testing null of no unit root for time period 1976:2-2006:4. P-Values as reported by TSP version 5.0 using seasonal dummy variables and with the lag order being selected by the program.

b: unemployment rate by ILO definition

c: quarterly inflation rate for consumer prices.

For the inflation rate the evidence is more mixed. While the augmented weighted symmetric $\tau$ test and the Phillips-Perron test show a significant rejection of the null of a unit root, the augmented Dickey-Fuller test does not show a rejection. Results are not as clear as for the unemployment rate, but the literature suggests that the the augmented weighted symmetric $\tau$ test has more power than the augmented DickeyFuller test. We conclude that there is not sufficient evidence for a unit root in the inflation rates. Thus, most of our estimated specifications involve a stationary model for the inflation rates.

\subsection{State Space Model and Kalman Filter}

We estimate versions of the following state space model.

Observation equation for inflation rate:

$$
p_{t}=a(L) p_{t-1}-b(L)\left(U_{t}-U_{t}^{*}\right)+c z_{t}+\varepsilon_{t}
$$

State equation for TV-NAIRU:

$$
U_{t}^{*}=U_{t-1}^{*}+\mu_{t}
$$

where $\mu_{t}$ and $\varepsilon_{t}$ and $\mu_{t}$ are independent and stationary error terms over time. Because the unemployment rate seems to be an $\mathrm{I}(1)$ variable, we specify $U_{t}^{*}$ as an $\mathrm{I}(1)$ variable in the state equation. Because there is no compelling evidence for a unit root in $p_{t}$, we leave it to the data to decide whether the lag order polynomial $a(L)$ involves a unit root. Anticipating our results, note that our estimation results reject a unit root in $a(L)$. Therefore, we will calibrate the TV-NAIRU based on a tolerable annualized inflation rates of 2 percent.

We further investigate whether estimating jointly two observation equations, one for the inflation rate as above and one for a dynamic version of Okun's law, can improve 
the precision of our TV-NAIRU estimates. Formally, we estimate equations (7) and (8) together with

$$
\left(U_{t}-U_{t}^{*}\right)=\alpha(L)\left(U_{t}-U_{t}^{*}\right)+\beta(L)\left(y_{t}-y_{t}^{*}\right)+v_{t},
$$

where the output gap $\left(y_{t}-y_{t}^{*}\right)$ is the difference between log gdp and trend gdp, where the latter is estimated using the Hodrik-Prescott-filter.

We estimate the structural parameters $a(L), b(L), c, \sigma_{\mu}^{2}, \sigma_{\varepsilon}^{2}$ (and $\sigma_{v}^{2}, \operatorname{Cov}\left(\varepsilon_{t}, v_{t}\right)$ ) by Maximum likelihood and Kalman filtering. We report the estimated smooth NAIRU based on the full subsample for which the model is estimated. Our estimation approach accounts for the structural break caused by German unification in the following. We allow for a dummy variable for the post unification period 1990:3-2006:4 in all equations and we run the Kalman Filter separately for the time period before and after unification. All structural parameters are assumed constant over both time periods, expect for the variance of the change in the TV-NAIRU, $\sigma_{\mu}^{2}$, which we allow to differ. We add the log likelihood of the separate Kalman filter models before and after unification and we maximize it as a function of the structural parameters. The Kalman filter is initialized as follows: We estimate the inflation equation based on OLS with a third order polynomial in time. We estimate the average intercept for the first four years of data and transform it to obtain a prior estimate for the NAIRU and for its variance. Since we only report smoothed Kalman filter estimates based on the entire subsample used the choice of the priors is of little importance for the final estimates. We add the transformed coefficient for the post unification dummy (in the inflation equation) to the NAIRU in 1990:2 to start the Kalman filter in 1990:3 for the second subsample.

In order to assess the precision of our TV-NAIRU, we estimate confidence intervals taking account of both sources of the estimation error, (Hamilton (1994), chapter 13.7). First, we need to take account of the estimation error in the estimated structural parameters. We obtain this part of the estimation error but a parametric bootstrap (simulation method) by resampling from the asymptotic distribution of the estimated parameters. ${ }^{34}$ Our reported estimates are based on 300 resamples. Second, the Kalman filter extraction involves a prediction error for the unobserved state variable, the TVNAIRU. The mean squared error of this prediction error has to be added to the variance component due to the estimation error in the structural parameters. Fabiani and Mestre (2001) only take account of the first dimension of the estimation error and the study reports very narrow confidence intervals around the TV-NAIRU. Laubach (2001) estimates both dimensions and obtains very wide confidence bands. Schumacher (2007) shows the importance to take account of both dimensions in a Kalman filter framework. However, note that the necessity to take account of the prediction error inherent in the Kalman filter arises only when one literally wants to account for the randomness in $\mu_{t}$ in equation (8). If the Kalman filter were viewed a means to obtain smoothed estimates of a 'true' flexible time trend in $U_{t}^{*}$, then one would only need to take account of the first part of the estimation error induced by the estimation of the structural parameter and the prediction error from the Kalman filter could be ignored.

Note that the estimated sampling uncertainty for the estimator of the TV-NAIRU sug-

\footnotetext{
${ }^{34}$ For variance parameters, which have to be positive, we resample from the asymptotic distribution of the $\log$ of the variance and then take the exponential of the simulated values.
} 
gested in the next subsection implicitly only involves the first source of the estimation error in a Kalman filter framework. This has to be kept in mind when comparing the estimated confidence bands for the estimated TV-NAIRU.

\subsection{Partially Linear Model}

We suggest estimating a simple semiparametric, partially linear model of

$$
p_{t}=a(L) p_{t-1}-b(L) U_{t}+c z_{t}+g(t)+\varepsilon_{t}
$$

as a robust alternative for estimating the TV-NAIRU. $g(t)$ is specified as a smooth function of time. We use the semiparametric root-N-consistent estimator by Robinson (1988) to obtain the coefficient estimates for $a(L), b(L)$, and $c$ after differencing out the variable specific time trend (estimated through variable specific kernel regressions on time) from the left-hand-side variable and all regressors. $g(t)$ is then estimated based on the 'residual' obtained when plugging in the nonparametric time trends of all variables into the linear part of the regression. ${ }^{35}$ Finally, the estimated $\hat{g}(t)$ is divided by $\hat{b}(1)$ and adjusted for the tolerable annual inflation rate of 2 percent to obtain the TV-NAIRU.

The bandwidth is chosen by a cross-validation procedure where the predictions at time $t$ are based on observations which are more than four quarters apart (leave blocks of two years around a single observation out because of the lags in the estimated equation). This cross-validation procedure works well for all models with the quarterly inflation rate of consumer prices (DCPI) as dependent variable. However, the procedure yields implausibly small values for the bandwidths (and TV-NAIRUs with wide swings) when the annual inflation rate (fourth difference in logs) is used. For these models, we use the bandwidths from crossvalidation of the corresponding models estimated for the quarterly inflation rates.

Based on the asymptotic distribution results, inference is on the estimation error in the final estimation step. For the estimate of the variance-covariance of the coefficient estimates, one can ignore the estimation error in the first stage estimation of the nonparametric time trend in the left-hand-side variable and in all regressors. Vice versa, for the asymptotic distribution of the estimated $\hat{g}(t)$, one can ignore the estimation error of the coefficient estimates. Therefore, we use here a standard heteroscedasticity consistent estimate of the estimation error in the kernel regression in the third stage.

\section{Estimation Results}

In order to operationalize the NAIRU, we allow for a tolerable annual inflation rate of 2 percent when estimation does not impose a unit root in the inflation rate. Furthermore, all supply shock variables $z_{t}$ in the augmented Phillips curve model are calculated as deviation from their sample means. Our estimated model involve the three supply shock variables as displayed in table 4 :

\footnotetext{
${ }^{35}$ See Pagan and Ullah (1999) for details of this semiparametric estimator.
} 
(i) Relative inflation rate of imported raw materials: prawwedge,

(ii) change rate of price wedge (consumer prices divided by GDP deflator for the private sector): pwedge $_{t}$, and

(iii) rate of change of labor productivity minus trend rate of change: $\theta_{t}$.

Furthermore, we used the change in the tax wedge between total compensation and net earnings of the workers as additional supply shock variable. However, this wedge never proves signficantly positive and, in most cases, it shows an insignificant coefficient.

We do not use the contemporaneous unemployment rate in the Phillips curve equation because it is likely to be jointly determined with the current inflation rate. The choice of lag order for lagged regressors is driven mainly by significance of individual t-statistics. For the inflation equation, we include all lags of the inflation rates up to the last significant one. When only one lag of the unemployment rate is included, we use that lag with the highest $t$-statistic for the negative coefficient. In the specification allowing for persistence or hysteresis of the unemployment effect, we include the level of the unemployment rate lagged once and the first four lags of the change in the unemployment rate. The estimation of Okun's law uses a distributed lag in the unemployment rate and in the outgap gap.

Both equations involve quarterly dummy variables to capture seasonal effects. These dummy variables are centered such that the coefficients of the four quarter sum up to zero. The inflation equation also involves a dummy variable for the post unification period which is incoporated in the estimated TV-NAIRU. The specification of Okun's law also allows for a separate intercept and a dummy variable for the post unification period. However, the intercept and the post unification dummy in Okun's law do not enter our estimates for the TV-NAIRU, i.e. Okun's law is only used for pinning done the change in the TV-NAIRU over time but not its level. The reason for this are twofold. First, we want to base the level of the TV-NAIRU solely on the estimated Phillips curve. Second, the notion of a tolerable inflation rate can not be linked in a natural way to the specification of Okun's law. In total, we report the results of the ten estimated model specifications described in table 5 . The detailed estimation results and graphical representations of the estimated TV-NAIRU with 90 percent-confidence bands are provided in the appendix. We report up to four different estimates for each model specification of the Phillips curve.

1. The first estimate labelled 'Same variance before/after unification' provides the estimates of the state space model just for the Phillips curve assuming the same variance in the state equation $\sigma_{\mu}^{2}$ before and after unification.

2. The second estimate labelled 'Different variances before/after unification' provides the estimates of the state space model just for the Phillips curve assuming different variances in the state equation $\sigma_{\mu}^{2}$ before and after unification.

3. The third estimate labelled 'Output gap and different variances' involves the joint estimation of the Phillips curve as in 2. and of Okun's law. 
Table 3: Coefficient Estimates for Selected Model

\begin{tabular}{rrrrrr}
\hline & \multicolumn{5}{c}{ Model Specifications } \\
Coefficient & $1^{a}$ & $2^{a}$ & $4^{a}$ & $5^{a}$ & $6^{b}$ \\
\hline Inflation rates $^{c}$ & .5340 & .5110 & .4110 & .8720 & .7750 \\
& $(4.9)$ & $(4.7)$ & $(2.8)$ & $(20.7)$ & $(10.2)$ \\
Unemployment rate $^{d}$ & -.4930 & -.5190 & -.5710 & -.1520 & -.2030 \\
& $(3.9)$ & $(4.1)$ & $(3.6)$ & $(3.7)$ & $(2.4)$ \\
\hline & & Model & Specifications & \\
Coefficient & $7^{b}$ & $8^{b}$ & $9^{a}$ & $10^{a}$ & \\
\hline Inflation rates $^{c}$ & .1610 & .7030 & .4740 & .5110 & \\
& $(2.2)$ & $(8.6)$ & $(3.1)$ & $(2.6)$ & \\
Unemployment rate $^{d}$ & -.6170 & -.0870 & -.6450 & -.5620 & \\
& $(3.9)$ & $(0.9)$ & $(3.7)$ & $(3.0)$ & \\
\hline
\end{tabular}

t-statistics in parentheses below coefficient estimates.

a: Estimate 2 "Different variances before/after unification'.

b: Estimate 4 'Partially linear model' because estimate 2 did not converge or gave unreasonable results.

c: Sum of coefficients for lags 1-5 for models with distributed lag of inflation rates and coefficient on inflation expectation otherwise. d: Sum of coefficients for lags in level of unemployment rate.

4. The fourth estimate labelled 'Partially linear model' involves the semiparametric estimate of the Phillips curve.

Tables 6, 7, and 8 provide detailed parameter estimates of the 10 estimated models. Figure 5 involves the estimated TV-Nairu's. Due to space considerations, the tables only report one of the four estimates for all model specifications. For the Kalman Filter estimates, we report only the estimates for the inflation equation only (except for model 1, for which table 7 also reports the estimated parameters for the joint estimation of the inflation equation and Okun's law). Our discussion of results will focus on the second estimate and the fourth estimate. For models $6-8$, only the fourth estimate provides reasonable results. For the reported models, there is no evidence for remaining autocorrelation in the residuals of the estimated model (see Ljung-Box statistics in tables 6,7 , and 8). ${ }^{36}$

Model 1 involves a specification of the Phillips curve using only the unemployment rate lagged by three quarters but no distributed lag in the changes in the unemployment rate. Furthermore, we do not yet include the productivity variable $\theta_{t}$. The first and second estimate show a highly significant negative coefficient estimate for the unemployment rate around -.48/.49. The coefficients of the lagged inflation rate sum up to around .52/.53 and are significantly less than one. Thus, a specification with a unit root is not warranted. The supply shock variables price wedge and wedge for raw

\footnotetext{
${ }^{36} \mathrm{We}$ do not take a P-value of 0.045 as evidence for remaining autocorrelation in model 4 . To keep the comparability with the othe models, we prefer not to change the lag structure for the dependent variable in this case.
} 
materials show significantly positive coefficients. The variance of the change in the TV-NAIRU is estimated as .061, if the same variance is imposed, and this changes to .083 before unification and 0 after unification, when different variances are allowed for before and after unification. The variances are estimated with a large standard error of .044 for the first estimate and .066 for the second estimate before unification. ${ }^{37}$ The graphical representations of the estimated TV-NAIRU show an increase of the TVNAIRU from around 3 percent in the mid 1970's to around 6 percent in 1990. After unification, the constant TV-NAIRU for the second estimate lies at about 7 percent and it moves around that estimate for the first estimate. The confidence bands around the TV-NAIRU are quite wide reflecting in particular the imprecision of the variance estimates.

The third estimate of model 1 also includes the estimation of Okun's law (compare the second column in table 6 with table 7 ). In contrast to arguments in the literature (Laubach (2001) or Schumacher (2007)), we are unable to confirm that estimating such a joint model neither helps to pin down the TV-NAIRU more precisely nor to avoid a problem of estimating a zero variance. The estimated coefficients are quite similar to the first two estimates but the standard error of the variance estimate is of similar magnitude. However, the confidence bands around the TV-NAIRU proves much wider for this estimate, especially after unification.

The fourth estimate of model 1 involves the partially linear model. The TV-NAIRU is estimated with a much narrower confidence band than for the three other estimates. The level of the TV-NAIRU is somewhat higher for the late 1970's but quite similar afterwards, i.e. the estimated TV-NAIRU basically correspond after the initialization period of the Kalman filter estimates (subject to the estimation error involved). Note that one should not be mislead by the higher precision of the TV-NAIRU estimates for the partially linear model. In contrast to the Kalman filter estimates, the partially linear model does not involve the prediction error from the state equation, i.e. the confidence bands for this estimator only involve the parameter uncertainty.

We now turn to discuss shortly the results of models 2 to 9 .

Model 2 differs from model 1 by adding the productivity variable $\theta_{t}$ to the Phillips curve. The productivity variable shows a significantly negative coefficient which is in accordance with the literature (Gordon (1998), Dew-Becker and Gordon (2005)). Thus, a positive productivity shock reduces the inflation pressure. Otherwise, the estimated coefficients of the model and the TV-NAIRU are very similar to model 1.

Model 3 imposes that the coefficients of the lagged inflation rate sum up to one. As discussed above, this restriction is not justified by the data and the estimation of the state space models yields implausible results. The coefficient of the unemployment rate is small and not significant any more. The estimated TV-NAIRU is meaningless with huge confidence bands. The partially linear model yields somewhat more plausible results. However, they also differ considerably from models 1 and 2. We conclude that

\footnotetext{
${ }^{37}$ Note that the $t$-statistics for the variance estimates are not valid for testing whether the variance is zero and the estimation routine does not provide standard errors when the variance estimate is close to zero. This reflects the severe numerical problems in estimating the state space model. However, it is not necessarily the case that this is a reflection of the pile up problem - as discussed in the literature - because it is quite likely that the estimated TV-NAIRU is quite constant after unification.
} 
it is not appropriate to restrict the coefficients of the lagged inflation rate to sum up to one.

Model 4 extends model 2 in allowing for lagged changes of the unemployment rate to affect the inflation rate in order to test for persistence and hysteresis in the Phillips curve. The lagged unemployment rate proves again highly significant and of quite similar magnitude as in model 2. Nevertheless, the lagged changes of the unemployment rate are significant as well, thus implying strong deviations of the NAIRU from its longrun value. The estimation of the state space model results in a smaller, but positive variance estimate also after unification. As estimated TV-NAIRU, we only report the long-run value based on the coefficient estimate for the lagged unemployment rate. The estimated TV-NAIRU is quite similar as in model 2. However, there are two small noticeable differences. The NAIRU is slighter higher in the 1970's and it is not constant any more after unification because of the small positive variance. In fact, similar to the partially linear model, the TV-NAIRU now shows a decline in the 1990's until about the year 2000 and an increase between 2000 an 2006. However, these changes lie within the estimated confidence band.

From now on, we take model 4 as the preferred benchmark model.

Model 5 estimate model 4 for the annual inflation rate defined as the difference between the current cpi and the cpi lagged four quarters. The estimated variance of the state equation is much higher than before and the coefficient on the lagged unemployment rate is reduced but still significantly negative. The estimated TV-NAIRU is more volatile than in model four for estimate two. The results are implausible for estimate one and quite similar to model four in the case of the partially linear model.

The reason we estimated model 5 was to provide a benchmark for models 6 to 8 estimated for the restricted time period 1987:2 to 2004:4 for which data on the lagged inflation expectations are available. The inflation expectations involve expectations for 12 months, which is the reason why we now estimate the model based on annual inflation rates. Unfortunately, the state space model does not provide reasonable results for models 6 to 8 . The variances of the state equations tend to infinity whatever reasonable restrictions we imposed. Thus, we are restricted to report the results of the partially linear model. There were, however, also problems with the partially linear model in these cases, because the cross validation procedure yielded implausibly small bandwidths. Therefore, we used the same bandwidths as for model 4 .

Model 6 reestimates model 5 for the time period 1987:2 to 2004:4. The results differ somewhat from model 5 but they do not change substantially. The TV-NAIRU is swings more around after unification and is slightly higher than for the previous models. Model 7 uses the lagged inflation expectations, which involves the expectation for the last 12 months corresponding to the time period covered by the inflation rate on the left-hand-side of the Phillips curve. The coefficient on the inflation expectations is very low with a value of .161 and significantly far away from one. The coefficient on the lagged unemployment rate is quite high in absolute value and significantly negative. Model 8 uses the current inflation expectations, which involves the expectation for the future 12 months. This model is in line with the New Keynesian Phillips curve. The coefficient on inflation expectations is now fairly high with a value of .703. This reflects 
the fact that inflation expectations are calibrated based on the current inflation rate, see discussion above. The estimated effect of the level of unemployment is very small and insignificant. Correspondingly, no reasonable TV-NAIRU can be estimated. Since inflation expectations in model 8 are likely to be endogenous, we experimented with instrumental variable estimation using lagged inflation rates as instruments. However, this did not yield any reasonable estimates. ${ }^{38}$ Thus, we have to conclude that using inflation expectations does not help to estimate a Phillips cuve and the TV-NAIRU in a more satisfactory way than using lagged inflation rates. This is not a route to rescue a Phillips curve specified in the difference in actual inflation minus expected inflation.

Model 9 extends the benchmark model 4 by interacting the lagged unemployment rate with dummy variables that expected inflation lies between 1 and 2 percent or below 1 percent. The expected inflation is obtained as the fit of an OLS regression of inflation on its five lags, quarter dummy variables, and a third order polynomial in time. The fit of this variable closely tracks actual inflation. Inspired by the near rationality hypothesis in Akerlof (2002), model 9 is a heuristic way to test whether the Phillips curve becomes flatter when inflation lies below the tolerable inflation rate of 2 percent. In fact, we find that the evidence is in favor of this argument because the interaction terms introduced shows significantly positive coefficients and the coefficient is even larger for expected inflation below 1 percent compared to 1-2 percent. ${ }^{39}$ Correspondingly, the coefficient on the lagged unemployment rate is slightly larger in absolute value than estimated for model 4. The estimated TV-NAIRU for model 9, however, is again very similar to model 4. Thus, near rationality does not seem to have a substantial effect on the TV-NAIRU, which is calibrated at a tolerable inflation rate of 2 percent.

There is some evidence for an almost constant TV-NAIRU after unification and the confidence bands around the TV-NAIRU are fairly wide. Therefore, as model 10 we reestimated model 4 the Phillips curve for the post unification period with constant coefficients. The estimated coefficients are quite similar to model 4 with some exceptions. In particular, the sum of coefficients on the lagged inflation rates and the coefficient on the lagged level of the unemployment rate are of similar magnitude. Correspondingly, we obtain a constant NAIRU of around 7.2 percent based on model 10. The estimation error, however, is quite large which the width of the 90 percent-confidence band being around 1 percentage point.

Summarizing our results, we arrive at the following conclusions. If one is willing to operationalize the TV-NAIRU at a tolerable inflation rate of 2 percent, it is possible to estimate a TV-NAIRU using a state space model for the entire sample period accounting for German unification. Estimates on a partially linear model provide similar point estimates for the TV-NAIRU during most of the time period. The TV-NAIRU for the ILO unemployment rate lies between 7 and 8 percent for post unification Germany. Estimation of a Phillips curve with the coefficients on the lagged inflation rates summing up to one is not supported by the data. Estimation of the state space models involves numerical problems when restricting the time period to the period for which

\footnotetext{
${ }^{38}$ Detailed results for the partially linear model are available upon request.

${ }^{39}$ We also estimated a specification with an additional interaction term for expected inflation between 2 and 3 percent. The corresponding coefficient proved positive but insignificant. The point estimate was less than half of the estimate for the interval 1 to 2 percent. The detailed results are available upon request.
} 
inflation expectations are available and it is not possible to estimate a TV-NAIRU this way. Based on the partially linear model, lagged inflations expectations do not show a coefficient even close to one but estimation of a TV-NAIRU of similar size as for the specification with lagged inflation rates is possible. Estimation of a Phillips curve using current inflation expectations inspired by the New Keynesian Phillips curve did not prove successful. In accordance with Akerlof's (2002) near rationality hypothesis, we find evidence for a flatter Phillips curve when inflation is low. However, this leaves our estimated TV-NAIRU basically unaffected. We can not determine precisely in a statistical sense whether the TV-NAIRU has been constant since German unification. However, the evidence does not show a secular increase of NAIRU since 1990 which is in contrast to the trends before 1990. This result is somewhat surprising in light of the upward trend in unemployment since 1990. Assuming the NAIRU to be constant after 1990 would result in an estimate of 7.2 percent.

\section{$7 \quad$ Final Remarks}

By any measure, simple or complex, the NAIRU is very hard to determine and this holds especially for Germany. We provide estimates of a time-varying NAIRU taking account of the structural break caused by German unification based on the Kalman Filter and on a partially linear model as two alternatives. The estimates presented in this paper suggest that the NAIRU in Germany is currently around 7 percent if the definition of unemployment follows the concept of the ILO or some 9 percent if measured according to the procedure applied by the German Federal Labor Agency. In contrast to the consensus in the literature, our estimates suggest furthermore that the NAIRU in Germany has not increased since the early 1990's. While the figure of 7 percent for 2006 is in line with calculations by other institutions, one should be careful not to put too much emphasis on it. One of the most disturbing facts is that the sum of coefficients associated with expected inflation is far beyond unity whatever measure of expected inflation rates is employed, i.e., survey data or lagged distributions of past inflation rates. Therefore, either the NAIRU concept is not applicable to Germany or one has to make use of a tolerable inflation rate as it is done in this paper with a number of 2 percent following roughly the figures put forward by the European Central Bank.

Under these caveats some interesting features of the NAIRU for Germany emerge from our estimates. The NAIRU depends on supply shocks such as changes of the relative import prices of raw materials and of the price wedge between consumption prices and the GDP deflator as well as deviations of actual productivity changes from their trend values.

Moreover, there is evidence for persistence effects of unemployment (but not for full hysteresis). In addition, the concept of near rationality is to some extent supported by our estimates, i.e., the role of (expected) inflation rates is positively related to their values. Put differently, the Phillips curve becomes the more steeper the higher expected inflation rates.

Taken together, there is every reason to use the NAIRU only as one of the tools to 
determine the unobservable natural rate of unemployment. Despite these caveats, on the positive side, we provide evidence that our estimated NAIRU for Germany at a tolerable inflation rate of 2 percent has remained fairly stable since the early 1990's. 


\section{References}

Akerlof, G.A. (2002) 'Behavioral Macroeconomics and Macroeconomic Behavior', American Economic Review 92(3), 411-433.

Akerlof, G.A., W.T. Dickens and G.L. Perry (2000) 'Near-Rational Wage and Price Setting and the Long-Run Phillips Curve', Brookings Papers on Economic Activity 1:2000, 1-60.

Dew-Becker, I. and R.J. Gordon (2005) 'Where did the productivity growth go? Inflation dynamics and the distribution of income', Brookings Papers on Economic Activity.

Fabiani, S. and R. Mestre (2001) 'A System Approach for Measuring the Euro Area NAIRU', ECB, Working Paper No. 65.

Franz, W. (1984) 'Inflation und interindustrielle Lohnstruktur', IFO-Studien 30(2), 81-106.

Franz, W. (1987) 'Hysteresis, Persistence and the NAIRU: An Empirical Analysis for the Federal Republic of Germany', in: R. Layard and L. Calmfors (eds.), The Fight Against Unemployment, Cambridge, Mass. (MIT-Press), 91-122.

Franz, W. (2005) 'Will the (German) NAIRU Please Stand Up?', German Economic Review 6(2), 131-153.

Franz, W. and R.J. Gordon (1993) 'German and American Wage and Price Dynamics: Differences and Common Themes', European Economic Review 37(4), 719-762.

Galí, J. and M. Gertler (1999) 'Inflation Dynamics: A Structural Econometric Analysis', Journal of Monetary Economics 44(2), 195-222.

Gerberding, C. (2001) 'Der Informationsgehalt von Umfragedaten zur erwarteten Preisentwicklung für die Geldpolitik', Deutsche Bundesbank, Volkswirtschaftliches Forschungszentrum, Diskussionspapier 09/01, Frankfurt/Main.

Gerberding, C. (2007) 'Household versus Expert Forecasts of Inflation: New Evidence from European Survey Data', in: P. Sinclair (ed.), The Role of Inflation Expectations in Modelling and Monetary Policy Making, London (forthcoming).

Gordon, R.J. (1997) 'The Time-Varying NAIRU and its Implications for Economic Policy', Journal of Economic Perspectives 11(1), 11-32.

Gordon, R.J. (1998) 'Foundations of the Goldilocks Economy: Supply Shocks and the Time-Varying NAIRU', Brookings Paper of Economic Activity 1998:2, 297346.

Laubach, Th. (2001) 'Measuring the NAIRU: Evidence from Seven Economies', Review of Economics and Statistics 83(2), 218-231.

Logeay. C. and S. Tober (2006) 'Hysteresis and the NAIRU in the Euro Area', Scottish Journal of Political Economy, 53(4), 409-429. 
Logeay. C. and S. Tober (2007) 'Explaining the Time-varying NAIRU in the Euro Area', in: G.L. Mazzi and G. Savio (eds.), Growth and Cycle in the Eurozone, 379-390.

Mankiw, N.G. (2001) 'The Inexorable and Mysterious Tradeoff between Inflation and Unemployment', Economic Journal 111 (No. 471), C45-C61.

Pagan, A. and A. Ullah (1999) 'Nonparametric Econometrics', Cambridge University Press.

Robinson, P. (1988) 'Root-N-Consistent Semiparametric Regression', Econometrica, 56(4), 931-954.

Sargent, T.J. (1971) 'A Note on the "Accelerationist" Controversy', Journal of Money, Credit and Banking 3(3), 721-725.

Schreiber, S. and J. Wolters (2007) 'The long-run Phillips curve revisited: Is the NAIRU framework data-consistent?', Journal of Macroeconomics, 29, 355-367.

Schumacher, C. (2007) 'Measuring uncertainty of the euro area NAIRU: Monte Carlo and empirical evidence for alternative confidence intervals in a state space framework', Empirical Economics, forthcoming.

Snower, D.J. and M. Karanassou (2002) 'An Anatomy of the Phillips Curve', Institute for the Study of Labor (IZA), Discussion Paper No. 635, Bonn.

Staiger, D., J.H. Stock and M.W. Watson (1997a) 'How Precise are the Estimates of the Natural Rate of Unemployment?', in: C.D. Romer and D.H. Romer (eds.), Reducing Inflation. Motivation and Strategy, Chicago (University Press), 195-242.

Staiger, D., J.H. Stock and M.W. Watson (1997b) 'The NAIRU, Unemployment and Monetary Policy', Journal of Economic Perspectives 11(1), 33-49.

Stiglitz, J.E. (1997) 'Reflections on the Natural Rate Hypothesis', Journal of Economic Perspectives, 11(1), 3-10.

Stock, J.H. and M.W. Watson (1998) 'Median unbiased estimation of coefficient variance in a time-varying parameter model', Journal of the American Statistical Association, 93:441, 349-358. 


\section{Appendix}

Figure 1: Change of inflation rate (GDP deflator) and unemployment in Germany

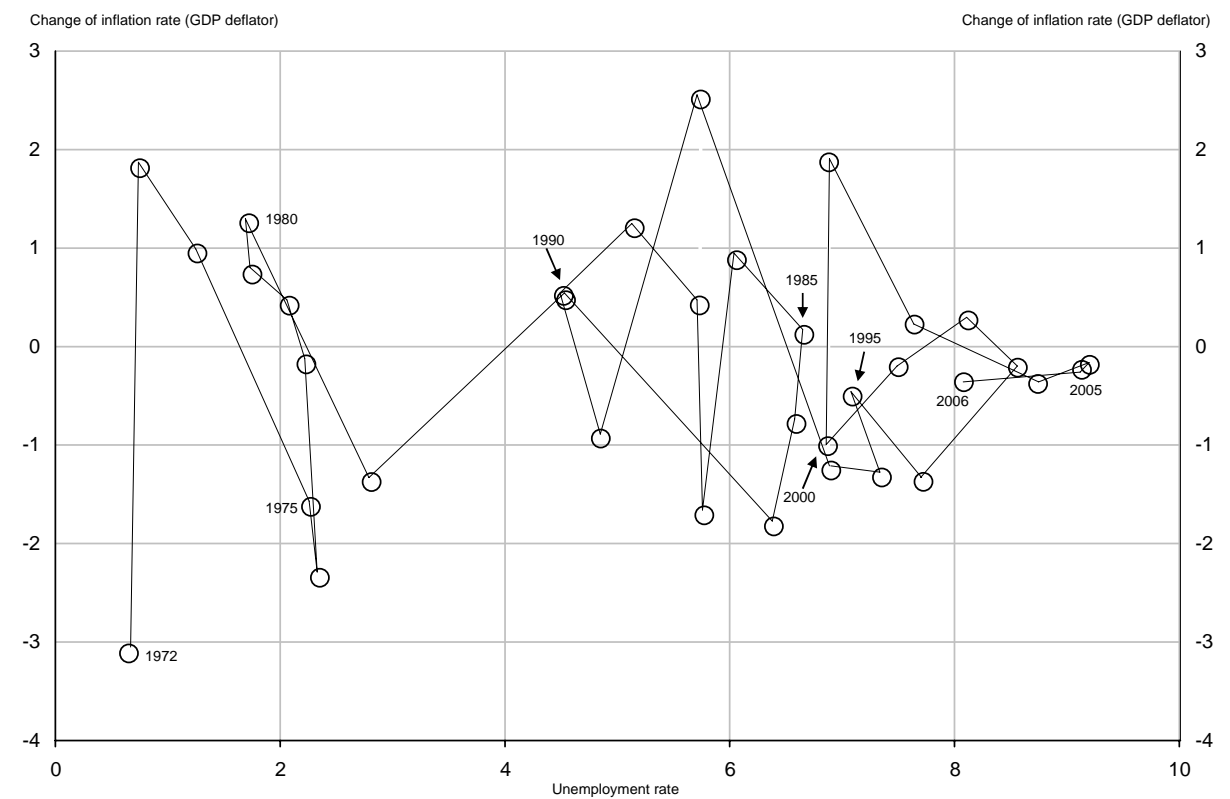

Figure 2: Change of inflation rate (CPI) and unemployment in Germany

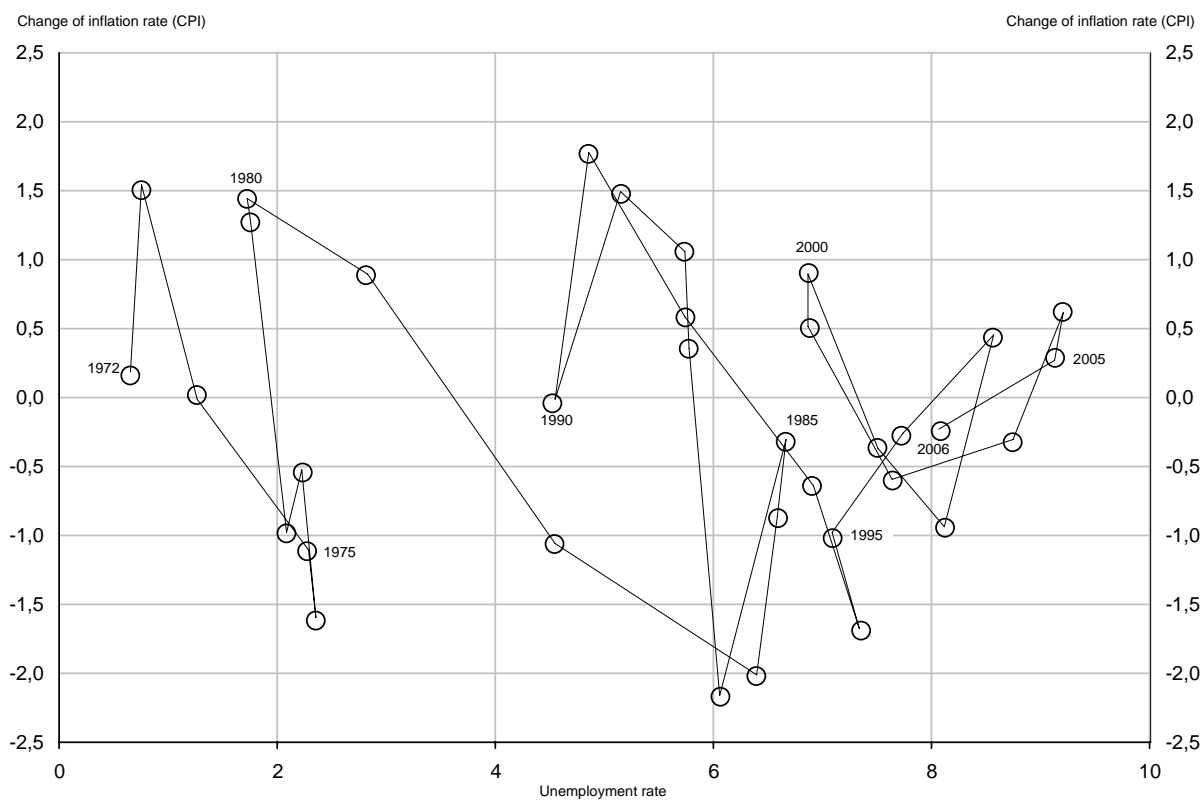


Figure 3: Inflation rate (GDP deflator) and unemployment in Germany

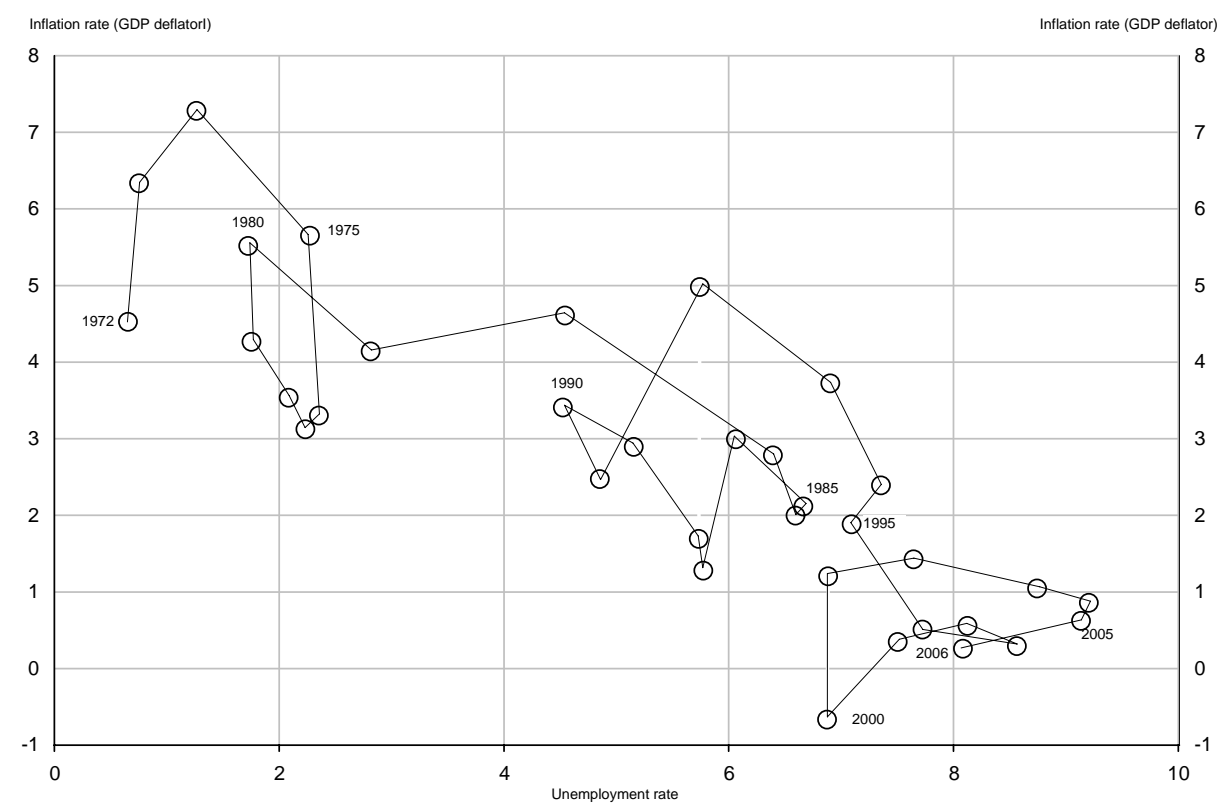

Figure 4: Inflation rate (CPI) and unemployment in Germany

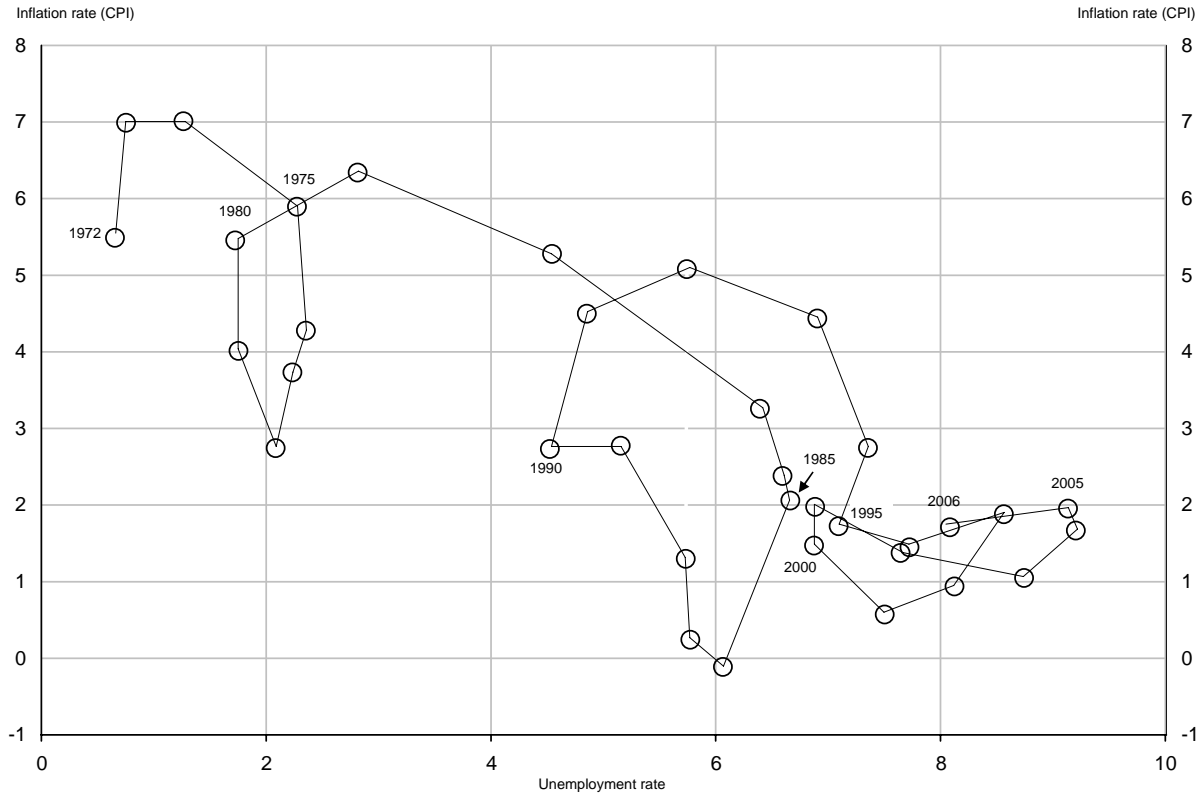


Table 4: Variable List

\begin{tabular}{|c|c|}
\hline Abbreviation & Variable (explanation) \\
\hline Q11 & $\begin{array}{l}\text { Variance of innovation in Nairu during period } 1 \text { (1976:2-1990:2 } \\
\text { - before unification) or during late period }(1987: 2-2006: 4)\end{array}$ \\
\hline Q12 & $\begin{array}{l}\text { Variance of innovation in Nairu during period } 2 \text { (1990:3-2006:4 } \\
\text { - after unification) }\end{array}$ \\
\hline $\operatorname{DQjC}(\mathrm{j}=1,2,3)$ & $\begin{array}{l}\text { centered quarter dummies such that quarter effect sum up to } \\
\text { unity (DQjC = DQj-DQ4 where DQk is dummy variable for } \\
\text { kth quarter) }\end{array}$ \\
\hline DCPI & $\begin{array}{l}\text { annualized quarter-by-quarter rate of CPI inflation, i.e. } p c_{t}= \\
400 \cdot\left(\log \left(c p i_{t}\right)-\log \left(c p i_{t-1}\right)\right) \text {, where } c p i_{t} \text { is the consumer price } \\
\text { index in quarter } t\end{array}$ \\
\hline $\operatorname{DCPIMj}(j=1,2, .)$. & jth lag of $p c_{t}$, i.e. $p c_{t-j}$ \\
\hline $\mathrm{D} 4 \mathrm{CPI}$ & $\begin{array}{l}\text { annual rate of CPI inflation, i.e. } p 4 c_{t}=100 \cdot\left(\log \left(c p i_{t}\right)-\right. \\
\left.\log \left(c p i_{t-4}\right)\right)\end{array}$ \\
\hline $\mathrm{D} 4 \mathrm{CPIMj}(\mathrm{j}=1,2, .)$. & jth lag of $p 4 c_{t}$, i.e. $p 4 c_{t-j}$ \\
\hline DE_ID_EXP & expected annual rate of CPI inflation for next 12 months \\
\hline $\operatorname{ELQMj}(j=1,2, .)$. & jth lag of unemployment rate $U_{t}$, i.e. $U_{t-j}$, by ILO definition \\
\hline DPRICE_WEDGE & $\begin{array}{l}\text { change in price wedge pwedge } e_{t}=\log \left(c p i_{t} / p y_{t}\right)- \\
\log \left(c p i_{t-1} / p y_{t-1}\right) \text { where } p y \text { is deflator of private GDP (without } \\
\text { government) }\end{array}$ \\
\hline DRAW_WEDGEC & $\begin{array}{l}\text { change in price wedge for raw material prices prawwedge } e_{t}= \\
\log \left(\operatorname{praw}_{t} / c p i_{t}\right)-\log \left(\operatorname{praw}_{t-1} / c p i_{t-1}\right) \text { where } \operatorname{praw}_{t} \text { is deflator } \\
\text { of raw material prices }\end{array}$ \\
\hline GRPROD & $\begin{array}{l}\text { rate of change of labor productivity minus trend rate of change } \\
\text { estimated by HP trend } \theta_{t}\end{array}$ \\
\hline DUNIFICATION & $\begin{array}{l}\text { Dummy variable for time period after unification 1990:3- } \\
\text { 2006:4 }\end{array}$ \\
\hline YGAP & output gap, i.e. deviation of log gdp from its HP trend \\
\hline
\end{tabular}

Definition of coefficients:

CDvarname : coefficient of regressor varname in inflation equation

CEvarname: coefficient of regressor varname in unemployment equation (Okun's law) 
Table 5: Estimated Model Specifications

Model Dep. Variable Time Period Specification

\begin{tabular}{|c|c|c|c|}
\hline 1 & DCPI & $76: 2-06: 4$ & lagged $\quad$ DCPI $\quad($ lags $1-5)$, \\
\hline & & & $\begin{array}{l}\text { ELQM3, DPRICE_WEDGE, } \\
\text { DRAW_WEDGEC, DUNIFICATION }\end{array}$ \\
\hline 2 & DCPI & $76: 2-06: 4$ & as 1 plus GRPROD \\
\hline 3 & DCPI & $76: 2-06: 4$ & $\begin{array}{l}\text { as } 2 \text {; restrict coeff. of lagged DCPI to } \\
\text { sum to one }\end{array}$ \\
\hline 4 & DCPI & $76: 2-06: 4$ & $\begin{array}{l}\text { as } 2 \text { plus lags in DELQ and ELQM1 } \\
\text { (test for hysteresis) }\end{array}$ \\
\hline 5 & D4CPI & $76: 2-06: 4$ & as 4 but lags in $\mathrm{D} 4 \mathrm{CPI}$ \\
\hline 6 & D4CPI & $87: 2-06: 4$ & as 4 but lags in D4CPI \\
\hline 7 & D4CPI & $87: 2-06: 4$ & $\begin{array}{l}\text { as } 4 \text { but DE_ID_EXP lagged by } 4 \text { quar- } \\
\text { ters (DE_ID_EXPM4) instead of lags in } \\
\text { D4CPI }\end{array}$ \\
\hline 8 & D4CPI & $87: 2-06: 4$ & $\begin{array}{l}\text { as } 4 \text { but DE_ID_EXP (DE_ID_EXP) in- } \\
\text { stead of lags in D4CPI }\end{array}$ \\
\hline 9 & DCPI & $76: 2-06: 4$ & $\begin{array}{l}\text { as } 4 \text { plus interaction of ELQM1 with } \\
\text { dummy variables for fitted inflation } \\
\text { (based on autoregressive model plus } \\
\text { seasonality) lying between } 1 \text { percent } \\
\text { and } 2 \text { percent (ELQM1L12) and below } \\
1 \text { percent (ELQM1LM1), respectively }\end{array}$ \\
\hline 10 & DCPI & $90: 3-06: 4$ & $\begin{array}{l}\text { OLS as } 4 \text { only for post unification pe- } \\
\text { riod (without DUNIFICATION) }\end{array}$ \\
\hline
\end{tabular}

Notes: Models 1-5 and 9 are estimated both using Kalman filter and as partially linear models. For models $6-8$, we only report the results of the partially linear models because the Kalman filter estimates did not converge properly or the results turned out implausible. Model 10 represents OLS estimates. 
Table 6: Estimated Models Inflation Equation Only

\begin{tabular}{|c|c|c|c|c|c|}
\hline \multirow[b]{2}{*}{ Time Period } & Model 1 & Model 2 & Model 3 & Model 4 & Model 5 \\
\hline & $76: 2-06: 4$ & $76: 2-06: 4$ & $76: 2-06: 4$ & $76: 2-06: 4$ & $76: 2-06: 4$ \\
\hline Dep. Variable & $p c_{t}$ & $p c_{t}$ & $p c_{t}$ & $p c_{t}$ & $p 4 c_{t}$ \\
\hline $\begin{array}{l}\text { Regressor/ } \\
\text { Parameter }\end{array}$ & $\begin{array}{c}\text { Coef. } \\
\text { (t-stat) }\end{array}$ & $\begin{array}{c}\text { Coef. } \\
\text { (t-stat) }\end{array}$ & $\begin{array}{c}\text { Coef. } \\
\text { (t-stat) }\end{array}$ & $\begin{array}{c}\text { Coef. } \\
\text { (t-stat) }\end{array}$ & $\begin{array}{c}\text { Coef. } \\
\text { (t-stat) }\end{array}$ \\
\hline$\sigma_{\mu}^{2}$ & .0834 & .0823 & .0093 & .0640 & 3.2055 \\
\hline${ }^{\mu}$ & $(1.3)$ & $(1.3)$ & $(-)$ & $(1.2)$ & $(1.1)$ \\
\hline$\sigma_{\mu}^{2}$ & $.0000^{b}$ & $.0000^{b}$ & .0000 & .0247 & $.0000^{b}$ \\
\hline Postunification & $(-)$ & $(-)$ & $(1.0)$ & $(.4)$ & $(-)$ \\
\hline \multicolumn{6}{|c|}{ Inflation Equation } \\
\hline Lagged inflation & .5346 & .5110 & - & .4112 & .8717 \\
\hline rates $^{a}$ & $(4.9)$ & $(4.7)$ & & $(2.8)$ & $(20.7)$ \\
\hline Change in Price & .0867 & .0805 & .0841 & .1049 & .0252 \\
\hline Wedge & $(2.5)$ & $(2.4)$ & $(2.2)$ & $(2.6)$ & $(2.2)$ \\
\hline Change in Price Wedge & .0171 & .0175 & .0188 & .0171 & .0034 \\
\hline for Raw Materials & $(4.7)$ & $(5.1)$ & $(5.0)$ & $(5.0)$ & $(3.1)$ \\
\hline Relative Change in & - & -.5492 & -.5394 & -.6067 & -.1220 \\
\hline Productivity & & $(3.1)$ & $(2.7)$ & $(3.2)$ & $(2.2)$ \\
\hline Postunification & .3473 & .5516 & .0326 & .9025 & .1301 \\
\hline Dummy & $(.6)$ & $(1.0)$ & $(-)$ & $(1.2)$ & $(1.1)$ \\
\hline$U_{t-1}$ & - & - & - & $\begin{array}{c}-.5710 \\
(3.6)\end{array}$ & $\begin{array}{c}-.1524 \\
(3.7)\end{array}$ \\
\hline$U_{t-3}$ & $\begin{array}{c}-.4936 \\
(3.9)\end{array}$ & $\begin{array}{c}-.5194 \\
(4.1)\end{array}$ & $\begin{array}{c}-.0184 \\
(.5)\end{array}$ & - & - \\
\hline$\Delta U_{t-1}$ & - & - & - & $\begin{array}{c}.0750 \\
(.2)\end{array}$ & $\begin{array}{c}.0714 \\
(.6)\end{array}$ \\
\hline$\Delta U_{t-2}$ & - & - & - & $\begin{array}{c}1.3443 \\
(3.5)\end{array}$ & $\begin{array}{c}.0682 \\
(.6)\end{array}$ \\
\hline$\Delta U_{t-3}$ & - & - & - & $\begin{array}{c}-.3740 \\
(1.0)\end{array}$ & $\begin{array}{c}.0759 \\
(.7)\end{array}$ \\
\hline$\Delta U_{t-4}$ & - & - & - & $\begin{array}{l}.6073 \\
(1.7)\end{array}$ & $\begin{array}{c}.0904 \\
(.8)\end{array}$ \\
\hline $\begin{array}{l}\text { Ljung-Box } \mathrm{Q}(4) \text {-statistic } \\
{[\mathrm{P} \text {-value }]}\end{array}$ & $\begin{array}{l}5.8768 \\
{[.209]}\end{array}$ & $\begin{array}{l}5.4412 \\
{[.245]}\end{array}$ & $\begin{array}{l}2.7751 \\
{[.596]}\end{array}$ & $\begin{array}{l}9.7689 \\
{[.045]}\end{array}$ & $\begin{array}{c}2.7592 \\
{[.599]}\end{array}$ \\
\hline
\end{tabular}

Notes:

All regressions include seasonal dummy variables and an intercept.

a: Sum of coefficients for lags 1-5 for models with distributed lag of inflation rates and coefficient on inflation expectation otherwise.

b: Variance estimated to be exactly zero. No estimate for standard error possible. 
Table 7: Model 1 - Joint Estimation of Inflation Equation and Okun's Law

\begin{tabular}{|c|c|c|c|}
\hline \multicolumn{4}{|c|}{ Model 1} \\
\hline \multicolumn{2}{|l|}{ Inflation Equation } & \multicolumn{2}{|c|}{ Okun's Law } \\
\hline Dep. Variable & $\overline{p c_{t}}$ & Dep.Var. & $U_{t}-U_{t}^{*}$ \\
\hline $\begin{array}{l}\text { Regressor/ } \\
\text { Parameter }\end{array}$ & $\begin{array}{l}\text { Coef. } \\
\text { (t-stat) }\end{array}$ & $\begin{array}{l}\text { Regressor/ } \\
\text { Parameter }\end{array}$ & $\begin{array}{l}\text { Coef. } \\
\text { (t-stat) }\end{array}$ \\
\hline $\begin{array}{l}\sigma_{\mu}^{2} \\
\text { Preunification } \\
\sigma_{\mu}^{2}(\text { Period 2) } \\
\text { Postunification }\end{array}$ & $\begin{array}{c}.0846 \\
(1.3) \\
0^{b} \\
(-)\end{array}$ & $\begin{array}{l}\operatorname{Cov}\left(\epsilon_{t}, v_{t}\right) / \sigma_{\epsilon} \\
\operatorname{Var}\left(v_{t}\right) / \sigma_{\epsilon}^{2}\end{array}$ & $\begin{array}{l}.0380 \\
(1.4) \\
.0683 \\
(5.4)\end{array}$ \\
\hline $\begin{array}{l}\text { Lagged inflation } \\
\text { rates }^{a} \\
\text { Change in Price } \\
\text { Wedge } \\
\text { Change in Price Wedge } \\
\text { for Raw Materials } \\
\text { Postunification } \\
\text { Dummy } \\
U_{t-3}\end{array}$ & $\begin{array}{l}.4555 \\
(4.1) \\
.0919 \\
(2.7) \\
.0170 \\
(4.8) \\
.6840 \\
(1.1) \\
-.5232 \\
(4.1)\end{array}$ & $\begin{array}{l}Y G A P_{t-1} \\
Y G A P_{t-2} \\
Y G A P_{t-3} \\
Y G A P_{t-4} \\
Y G A P_{t-5} \\
U_{t-1} \\
U_{t-2} \\
U_{t-3} \\
U_{t-4} \\
\text { Post Unification } \\
\text { Dummy }\end{array}$ & $\begin{array}{c}-.0439 \\
(3.2) \\
.0499 \\
(3.1) \\
-.0575 \\
(3.3) \\
.0611 \\
(3.6) \\
-.0274 \\
(2.0) \\
1.2743 \\
(13.4) \\
-.5308 \\
(3.7) \\
.4232 \\
(3.0) \\
-.2256 \\
(2.6) \\
.0573 \\
(.9)\end{array}$ \\
\hline $\begin{array}{l}\text { Ljung-Box } \mathrm{Q}(4) \text {-statistic } \\
{[\mathrm{P} \text {-value }]}\end{array}$ & $\begin{array}{c}8.7876 \\
{[.067]}\end{array}$ & & $\begin{array}{l}4.8980 \\
{[.179]} \\
\end{array}$ \\
\hline
\end{tabular}

Notes: see table 6. 
Table 8: Estimated Models Inflation Equation Only

\begin{tabular}{|c|c|c|c|c|c|}
\hline & Model $6^{c}$ & Model $7^{c}$ & Model $8^{c}$ & Model 9 & Model $10^{d}$ \\
\hline Time Period & $87: 2-06: 4$ & $87: 2-06: 4$ & $87: 2-06: 4$ & $76: 2-06: 4$ & $90: 3-06: 4$ \\
\hline Dep. Variable & $p 4 c_{t}$ & $p 4 c_{t}$ & $p 4 c_{t}$ & $p c_{t}$ & $p c_{t}$ \\
\hline $\begin{array}{l}\text { Regressor/ } \\
\text { Parameter }\end{array}$ & $\begin{array}{l}\text { Coef. } \\
\text { (t-stat) }\end{array}$ & $\begin{array}{l}\text { Coef. } \\
\text { (t-stat) }\end{array}$ & $\begin{array}{c}\text { Coef. } \\
\text { (t-stat) }\end{array}$ & $\begin{array}{l}\text { Coef. } \\
\text { (t-stat) }\end{array}$ & $\begin{array}{l}\text { Coef. } \\
\text { (t-stat) }\end{array}$ \\
\hline $\begin{array}{l}\sigma_{\mu}^{2} \\
\text { Preunification } \\
\sigma_{\mu}^{2} \\
\text { Postunification }\end{array}$ & - & - & - & $\begin{array}{l}.0475 \\
(1.1) \\
.0285 \\
(.6)\end{array}$ & - \\
\hline $\begin{array}{l}\text { Lagged inflation } \\
\text { rates }^{a}\end{array}$ & $\begin{array}{l}.7745 \\
(10.2)\end{array}$ & - & - & $\begin{array}{l}.4742 \\
(3.1)\end{array}$ & $\begin{array}{l}.5114 \\
(2.6)\end{array}$ \\
\hline $\begin{array}{l}\text { Expected Inflation } \\
\text { Rate Lag } 4\end{array}$ & & $\begin{array}{l}.1607 \\
(2.2)\end{array}$ & - & - & - \\
\hline $\begin{array}{l}\text { Expected Inflation } \\
\text { Rate (no lag) }\end{array}$ & - & - & $\begin{array}{l}.7028 \\
(8.6)\end{array}$ & - & - \\
\hline$U_{t-1}$ & $\begin{array}{l}-.2025 \\
(2.4)\end{array}$ & $\begin{array}{c}-.6166 \\
(3.9)\end{array}$ & $\begin{array}{c}-.0870 \\
(.9)\end{array}$ & $\begin{array}{c}-.6449 \\
(3.7)\end{array}$ & $\begin{array}{c}-.5617 \\
(3.0)\end{array}$ \\
\hline$U_{t-1} \cdot I\left(\widehat{p c}_{t} \in[1,2)\right)^{e}$ & - & - & - & $\begin{array}{l}.1134 \\
(2.1)\end{array}$ & - \\
\hline$U_{t-1} \cdot I\left(\widehat{p c}_{t}<1\right)^{e}$ & - & - & - & $\begin{array}{l}.1326 \\
(1.9)\end{array}$ & - \\
\hline$\Delta U_{t-1}$ & $\begin{array}{c}.0257 \\
(.1)\end{array}$ & $\begin{array}{c}-.0980 \\
(.2)\end{array}$ & $\begin{array}{c}-.3213 \\
(1.1)\end{array}$ & $\begin{array}{c}-.0090 \\
(.0)\end{array}$ & $\begin{array}{c}.6211 \\
(.7)\end{array}$ \\
\hline$\Delta U_{t-2}$ & $\begin{array}{l}.3002 \\
(1.8)\end{array}$ & $\begin{array}{l}.8182 \\
(1.9)\end{array}$ & $\begin{array}{c}.2123 \\
(.9)\end{array}$ & $\begin{array}{c}1.3335 \\
(3.5)\end{array}$ & $\begin{array}{c}1.4193 \\
(1.9)\end{array}$ \\
\hline$\Delta U_{t-3}$ & $\begin{array}{c}.1130 \\
(.6)\end{array}$ & $\begin{array}{l}.5514 \\
(1.2)\end{array}$ & $\begin{array}{l}.0929 \\
(.4)\end{array}$ & $\begin{array}{c}-.3028 \\
(.8)\end{array}$ & $\begin{array}{c}-1.1630 \\
(1.5)\end{array}$ \\
\hline$\Delta U_{t-4}$ & $\begin{array}{c}.1776 \\
(.9)\end{array}$ & $\begin{array}{l}.8869 \\
(2.1)\end{array}$ & $\begin{array}{l}.4199 \\
(1.5)\end{array}$ & $\begin{array}{l}.9838 \\
(2.5)\end{array}$ & $\begin{array}{l}.3616 \\
(.4)\end{array}$ \\
\hline Change in Price & .0321 & .0650 & .0466 & .0972 & .2148 \\
\hline Wedge & $(1.6)$ & $(1.8)$ & $(1.9)$ & $(2.5)$ & $(3.1)$ \\
\hline Change in Price Wedge & .0030 & .0001 & .0022 & .0163 & .0171 \\
\hline for Raw Materials & $(2.6)$ & $(.0)$ & $(1.4)$ & $(4.8)$ & $(3.2)$ \\
\hline Relative Change in & -.1711 & -.2602 & -.0591 & -.6443 & -1.1255 \\
\hline Productivity & $(1.7)$ & $(1.6)$ & $(.6)$ & $(3.5)$ & $(3.1)$ \\
\hline Postunification & .4253 & 1.3320 & .0027 & 1.0265 & - \\
\hline Dummy & $(1.9)$ & $(2.3)$ & $(-)$ & $(1.4)$ & \\
\hline $\begin{array}{l}\text { Ljung-Box Q(4)-statistic } \\
{[\mathrm{P} \text {-value }]}\end{array}$ & $\begin{array}{l}7.4397 \\
{[.114]}\end{array}$ & $\begin{array}{c}95.6166 \\
{[.000]}\end{array}$ & $\begin{array}{c}17.0330 \\
{[.002]}\end{array}$ & $\begin{array}{l}5.8641 \\
{[.210]}\end{array}$ & $\begin{array}{l}.5588 \\
{[.968]}\end{array}$ \\
\hline
\end{tabular}

Notes: see table 6 .

c: Estimates for partially linear model.

d: OLS - no time-varying coefficients.

e: The 'expected' inflation rate $\widehat{p c}_{t}$ is the predicted inflation rate based on an autoregression of $p c_{t}$ on five lags and seasonal dummy variables. 
Model 1

Figure 5: Nairu Estimates for Models 1-10

Nairu plus $90 \%$ confidence bands - Same Variance before/after Unification

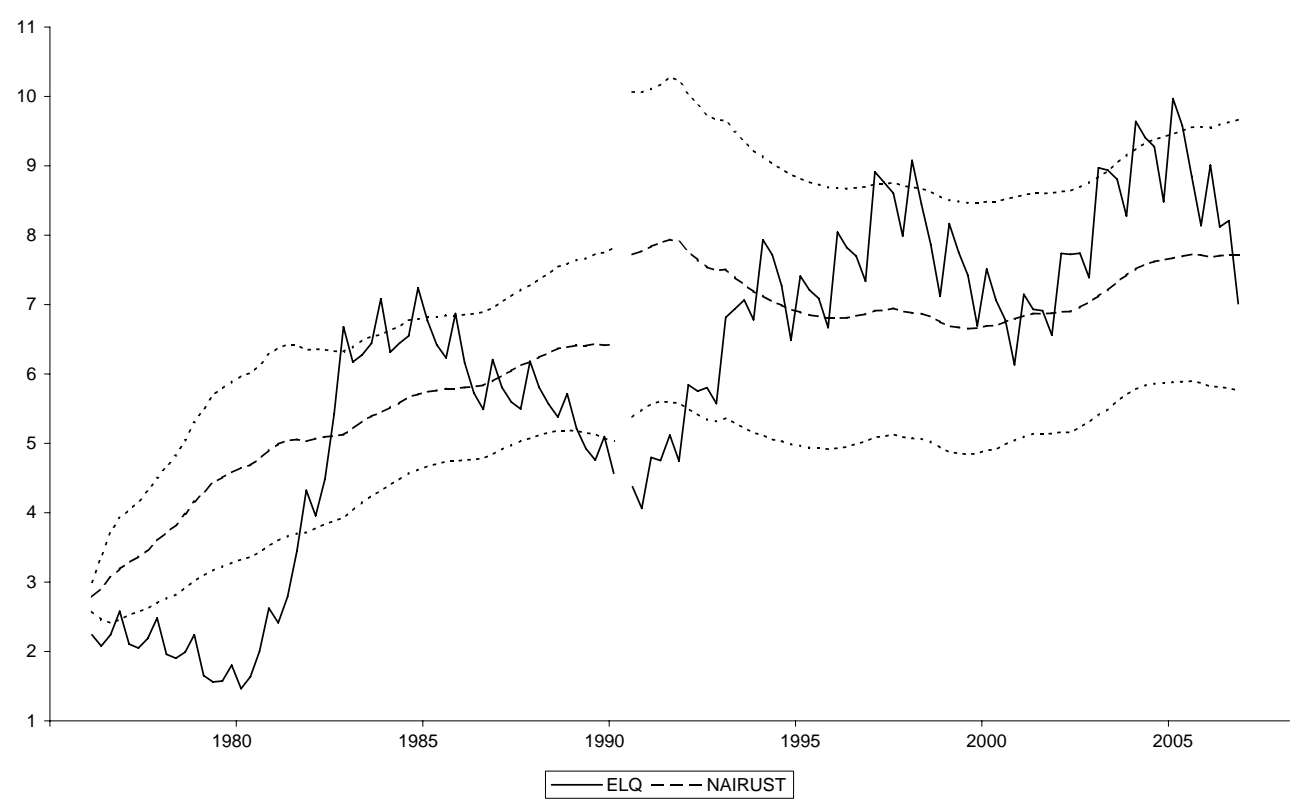

Nairu plus 90\% confidence bands - Different Variance before/after Unification

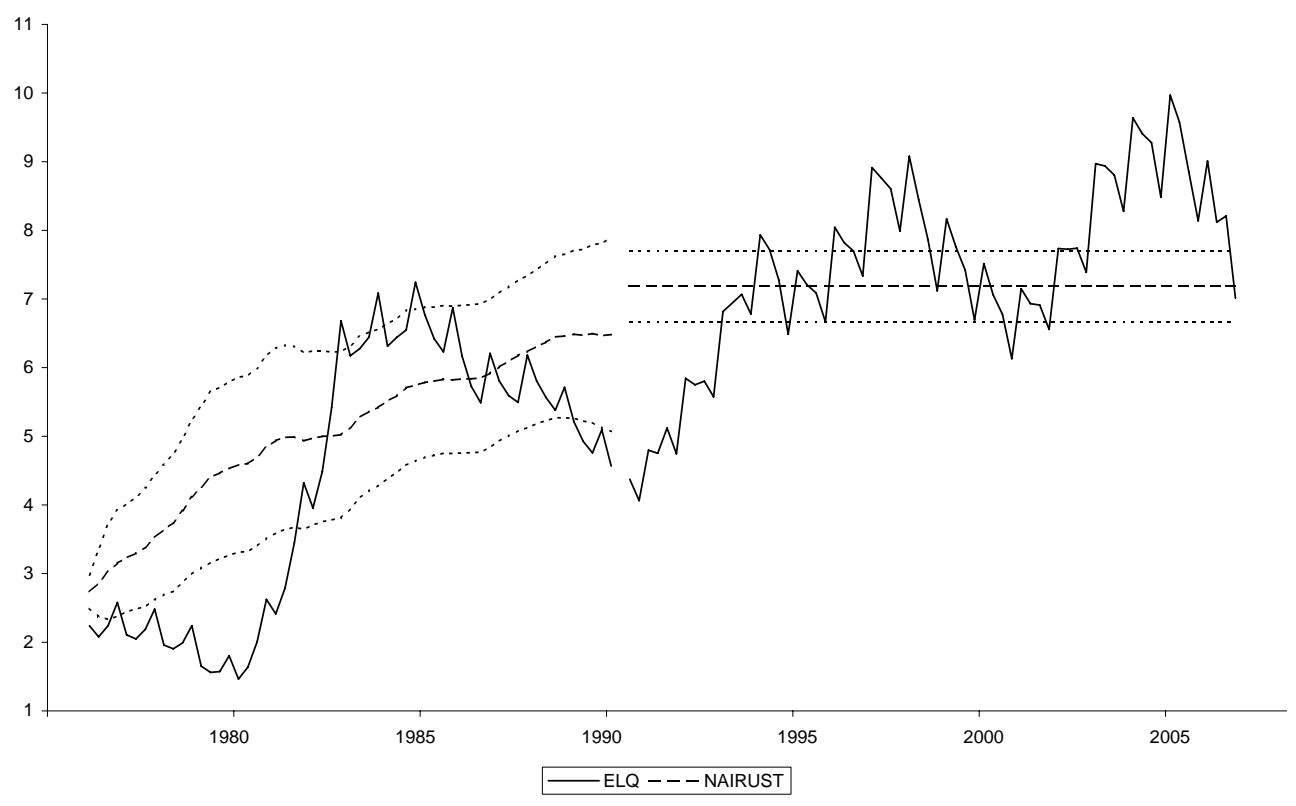


Nairu plus 90\% confidence bands - Output gap and different Variances

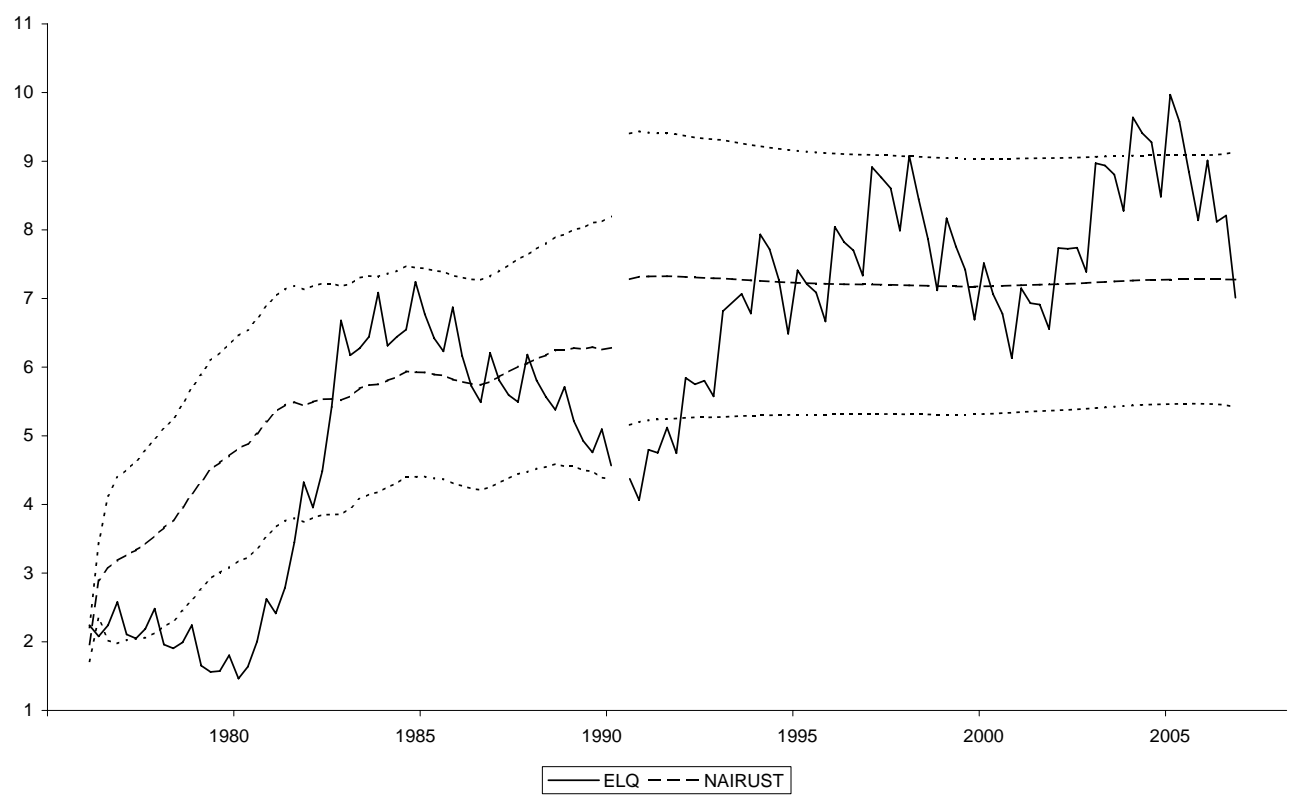

Nairu plus 90\% confidence bands - Partially linear model

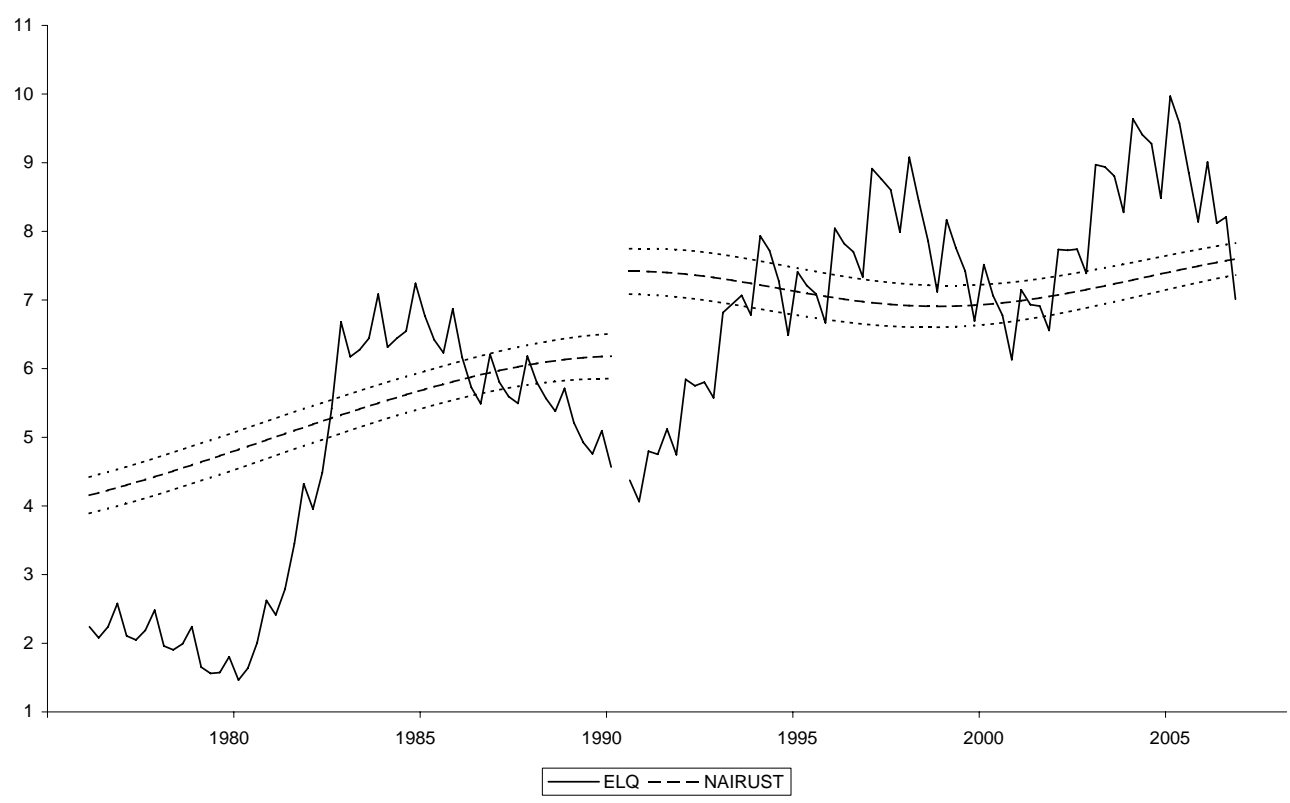




\section{Model 2}

Nairu plus 90\% confidence bands - Same Variance before/after Unification

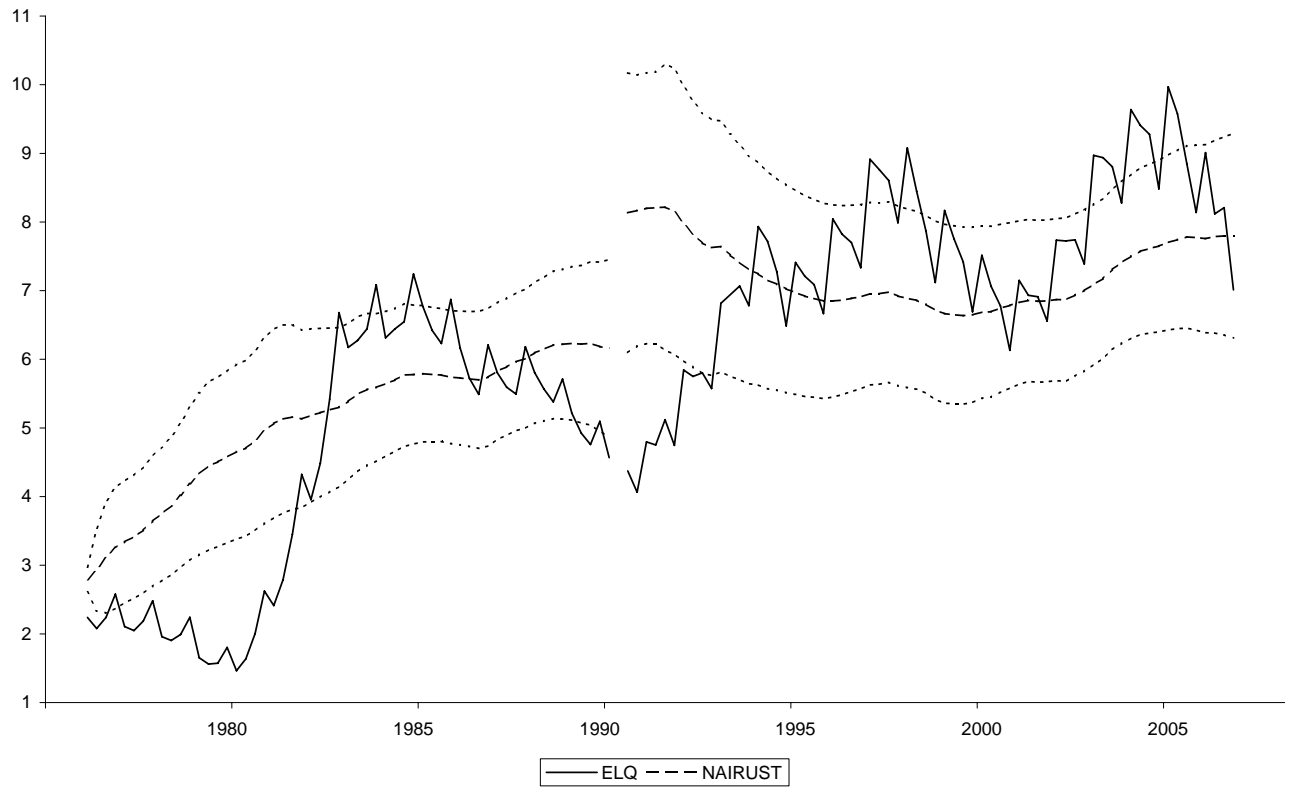

Nairu plus $90 \%$ confidence bands - Different Variances before/after Unification

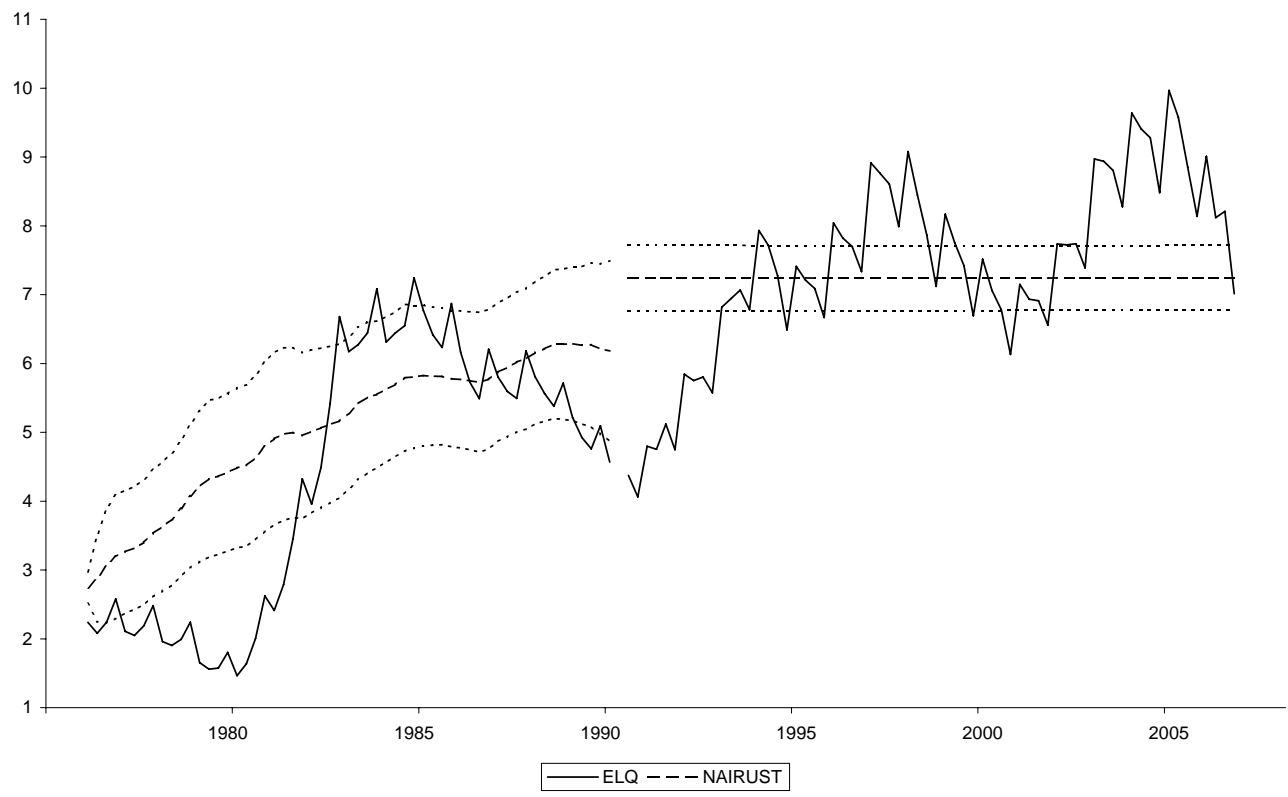


Nairu plus 90\% confidence bands - Output gap and different Variances

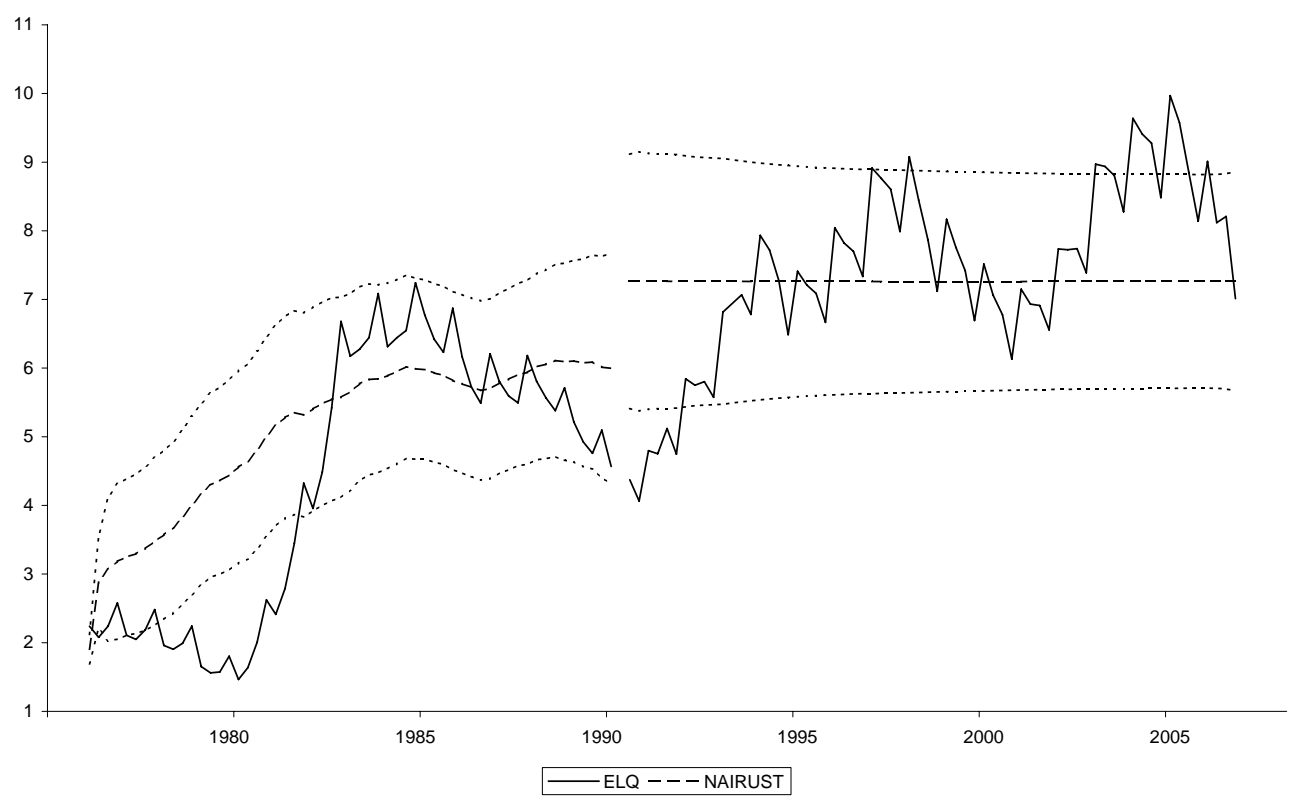

Nairu plus $90 \%$ confidence bands - Partially linear model

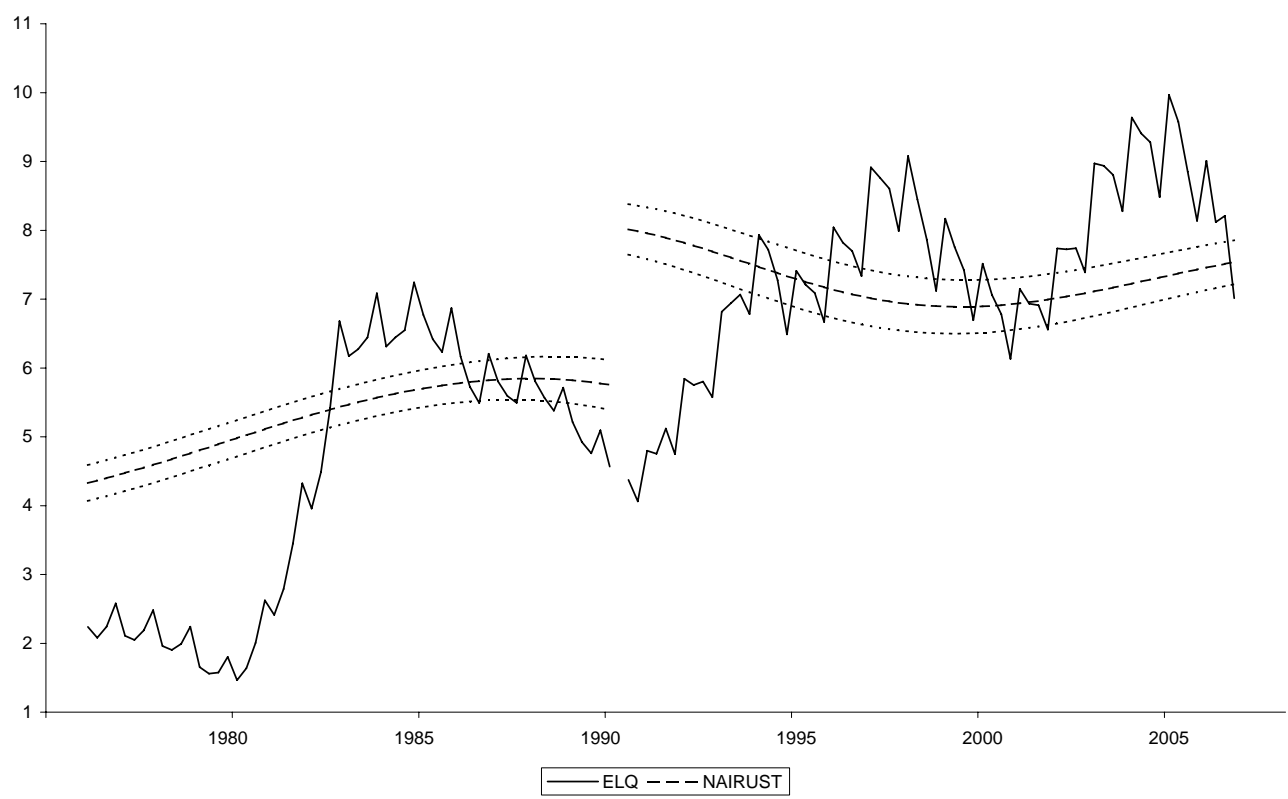




\section{Model 3}

Nairu plus $90 \%$ confidence bands - Different Variances before/after Unification

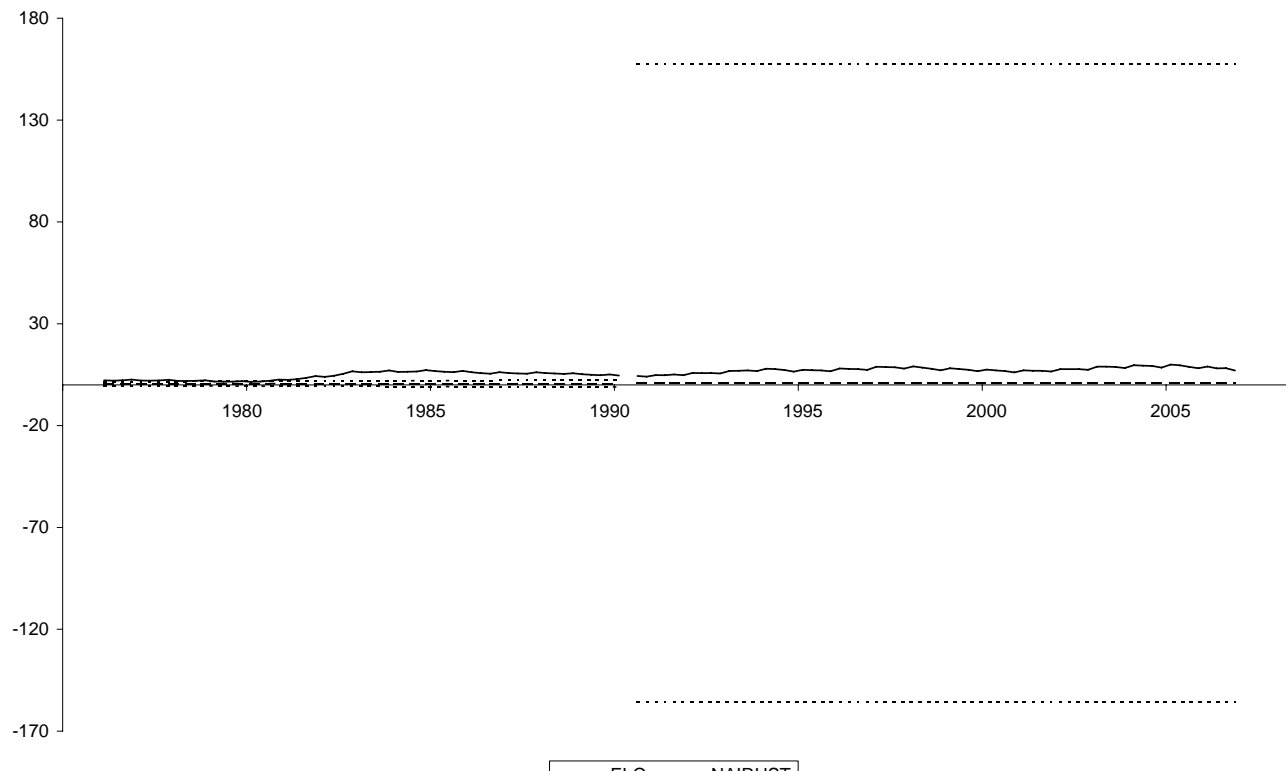

Nairu plus $90 \%$ confidence bands - Partially linear model

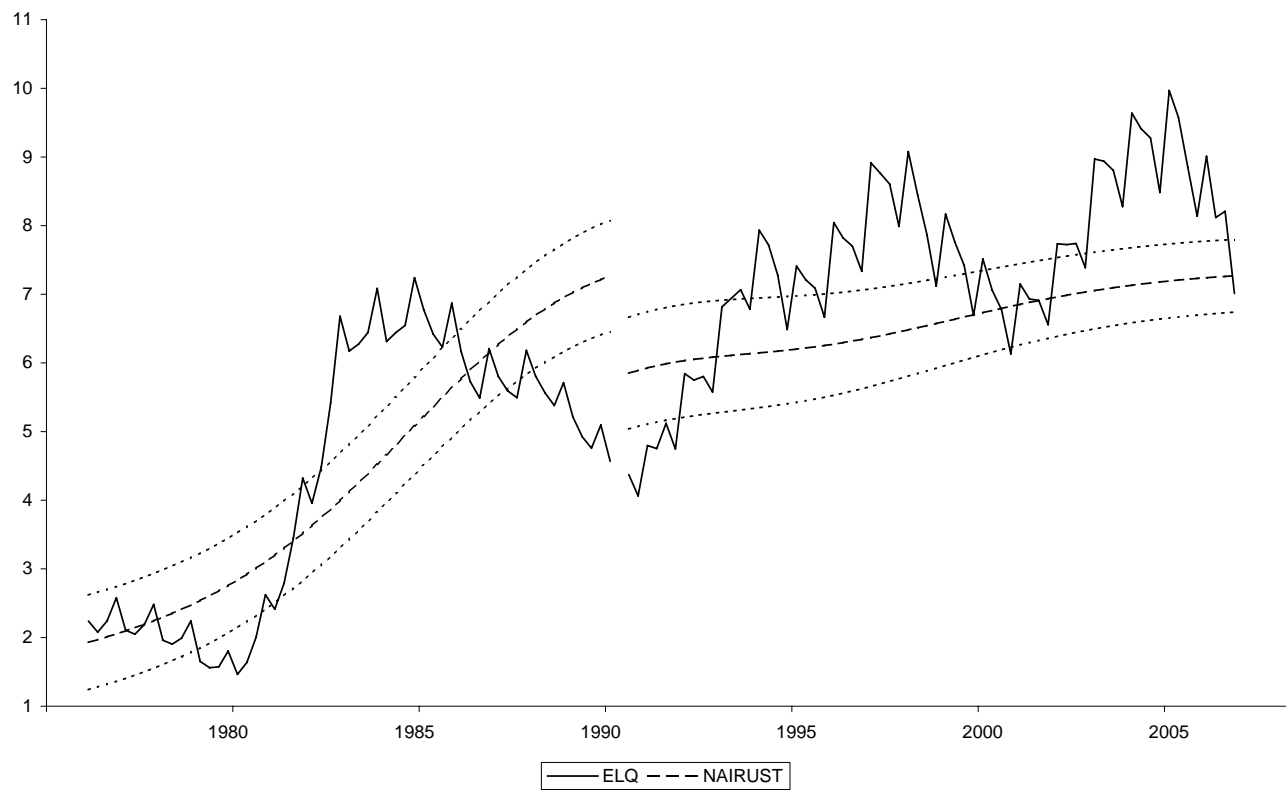




\section{Model 4}

Nairu plus 90\% confidence bands - Same Variance before/after Unification

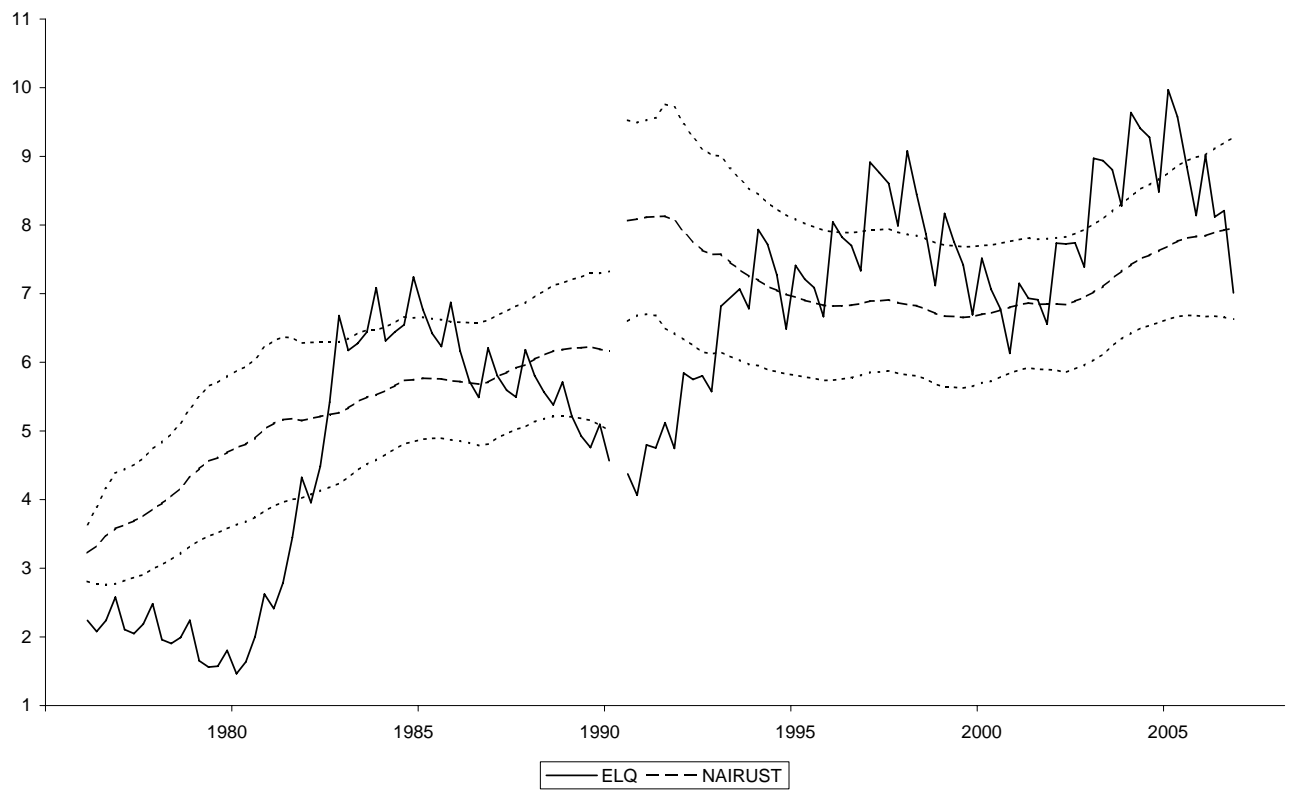

Nairu plus 90\% confidence bands - Different Variances before/after Unification

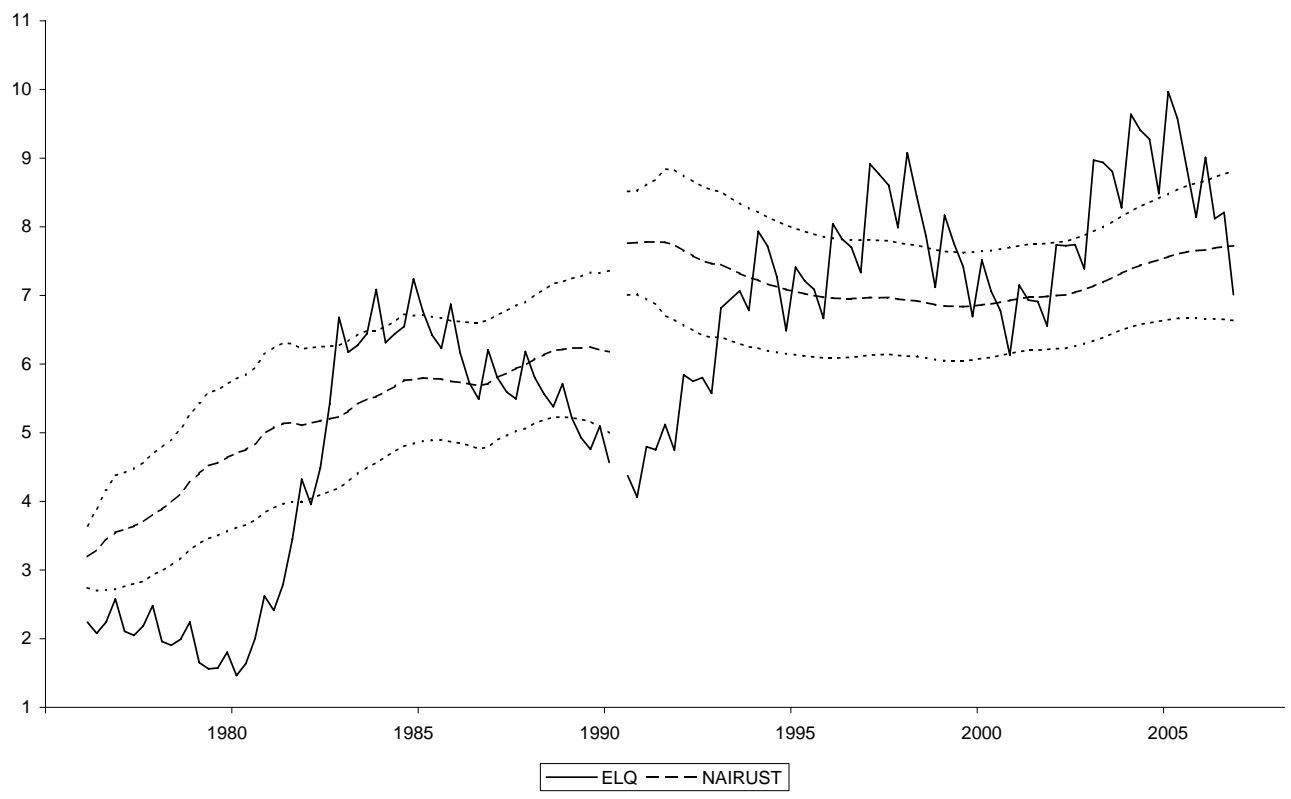


Nairu plus 90\% confidence bands - Output gap and different Variances

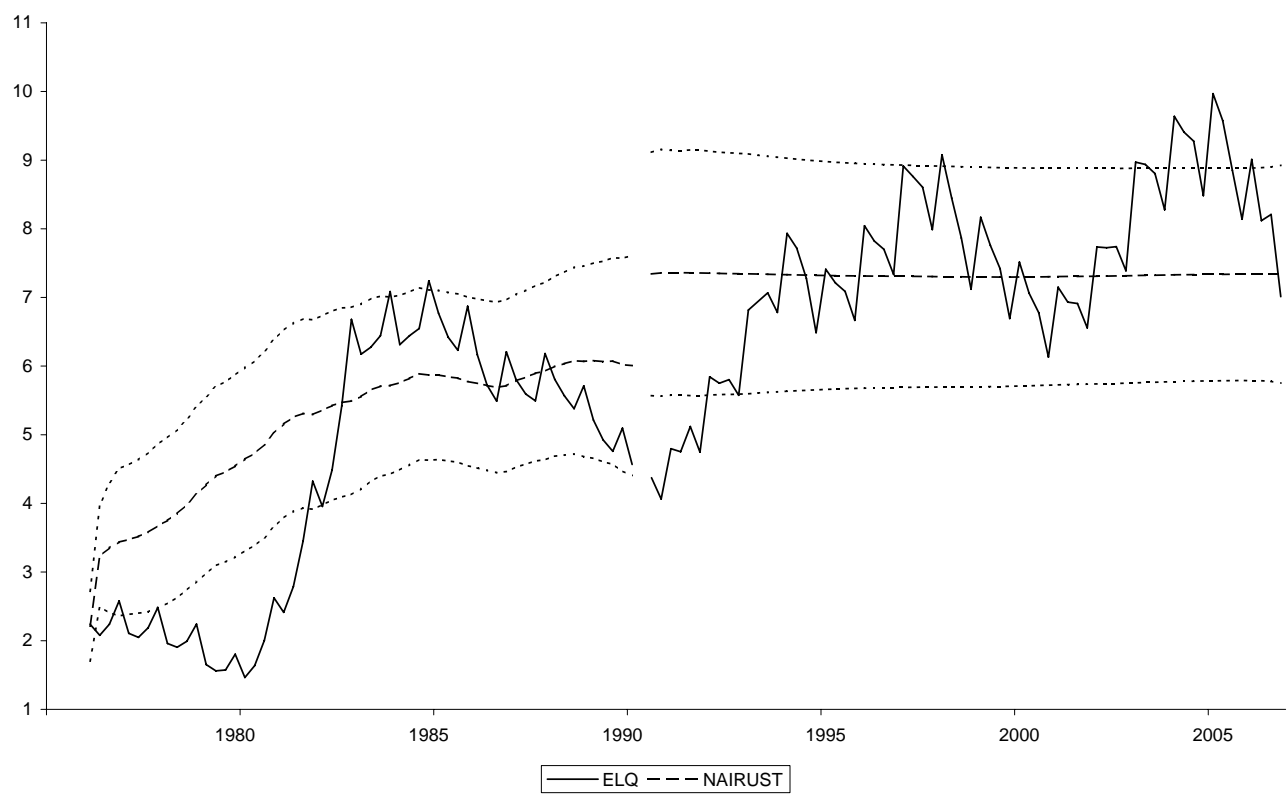

Nairu plus $90 \%$ confidence bands - Partially linear model

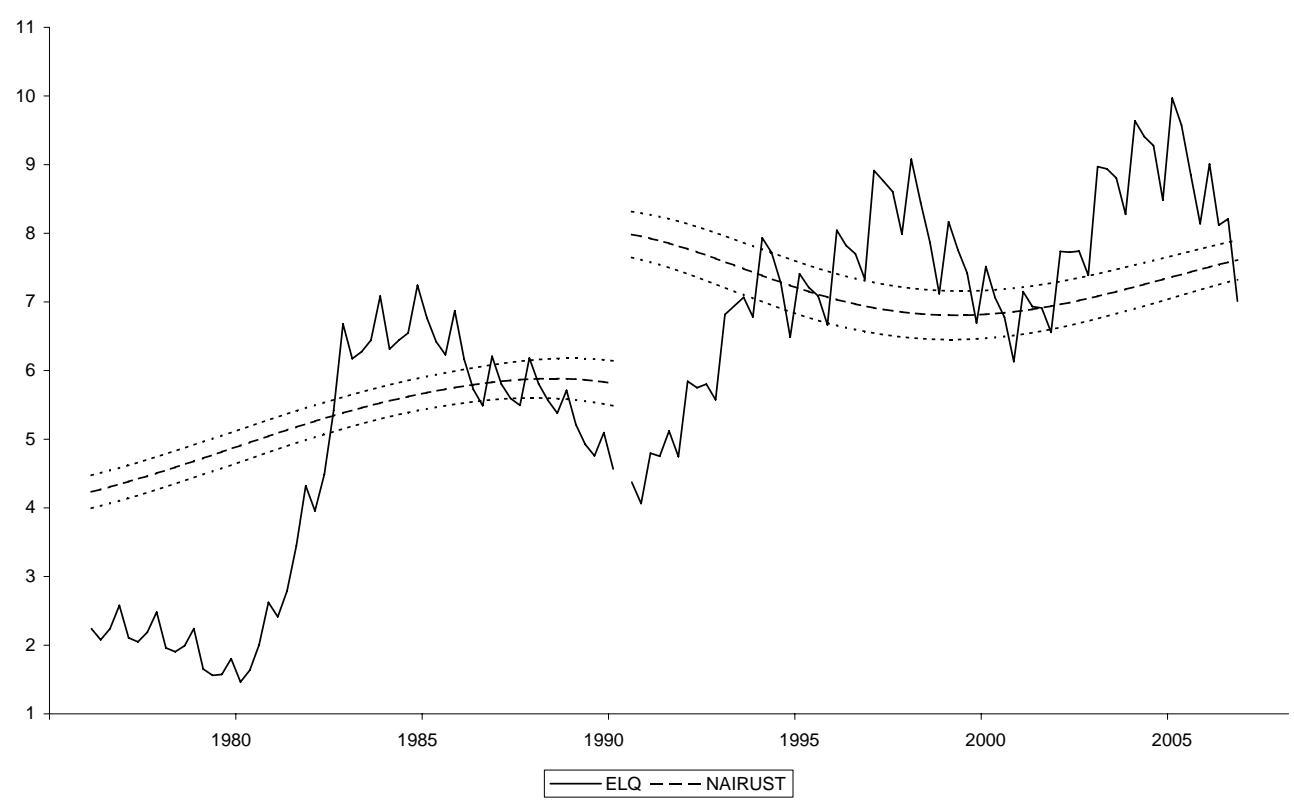




\section{Model 5}

Nairu plus 90\% confidence bands - Same Variance before/after Unification

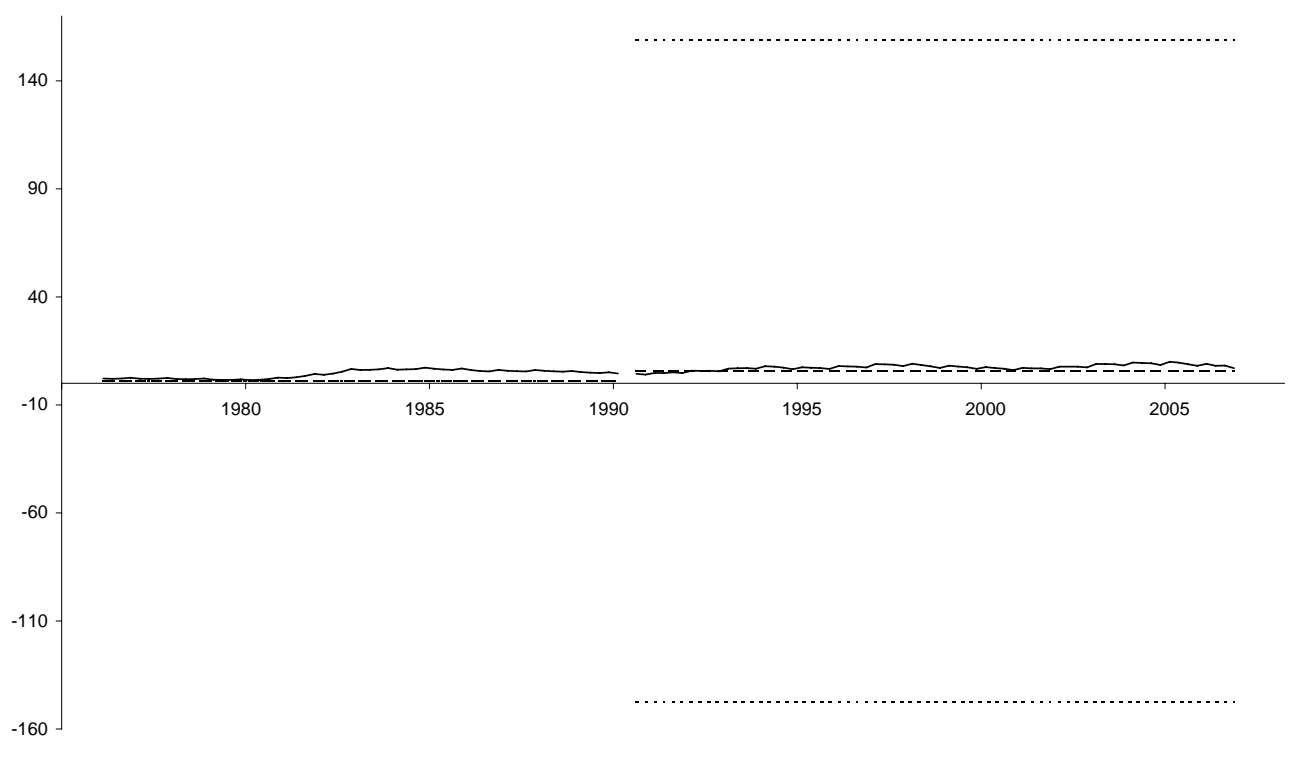

Nairu plus 90\% confidence bands - Different Variances before/after Unification

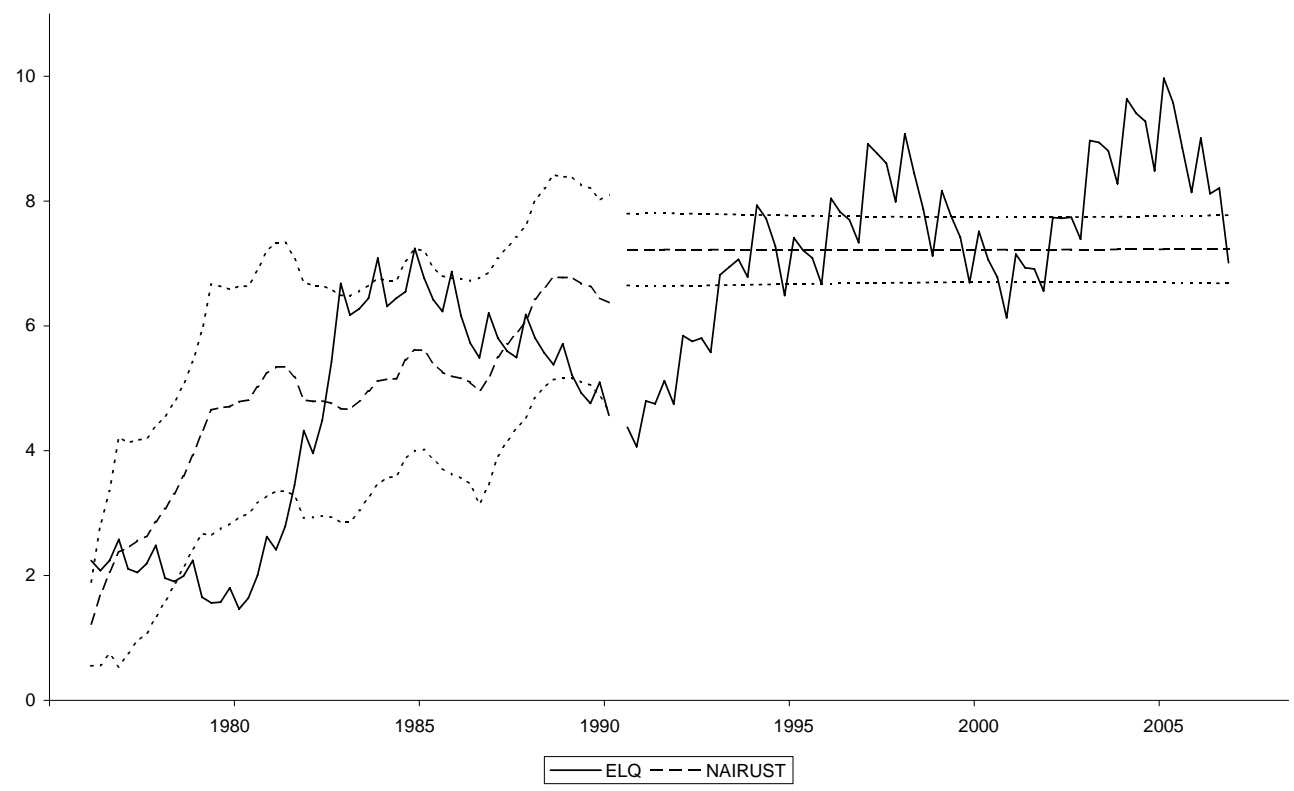


Nairu plus 90\% confidence bands - Partially linear model

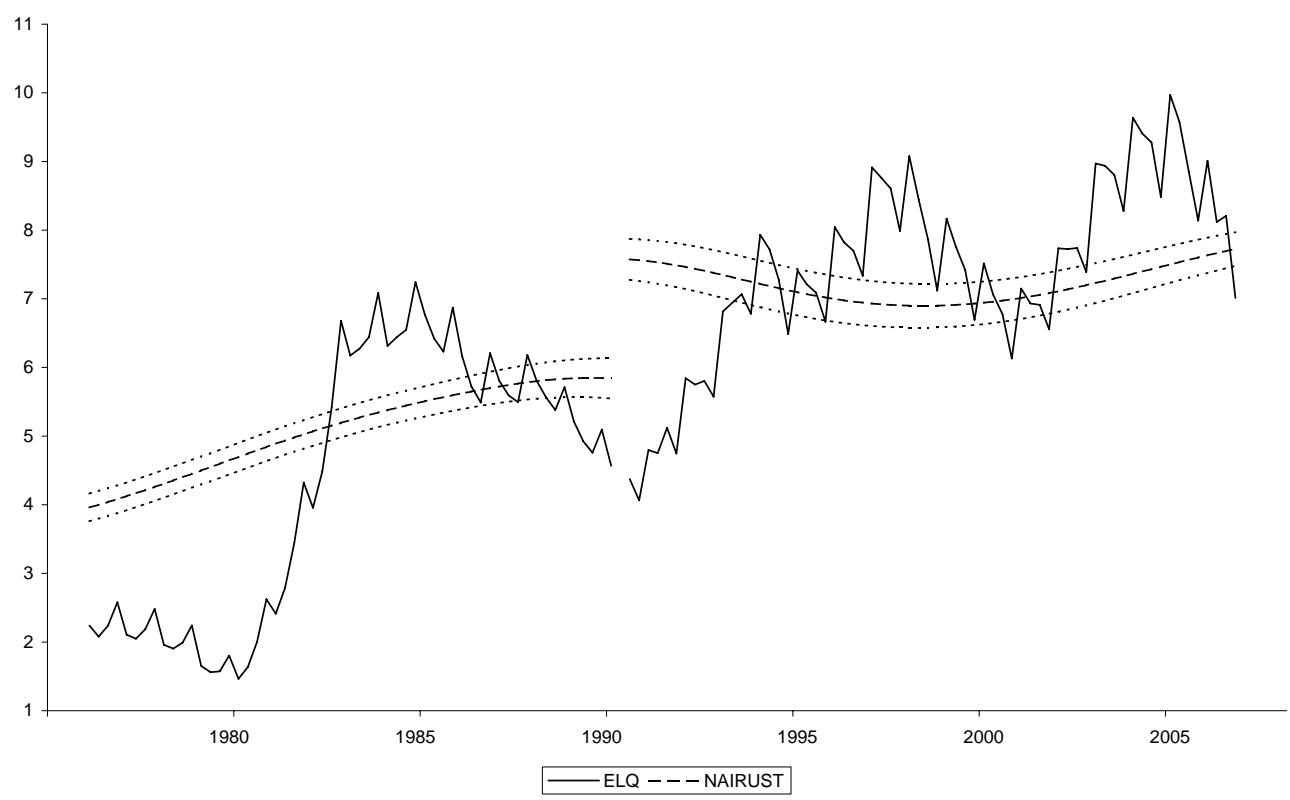

Model 6

Nairu plus $90 \%$ confidence bands - Partially linear model

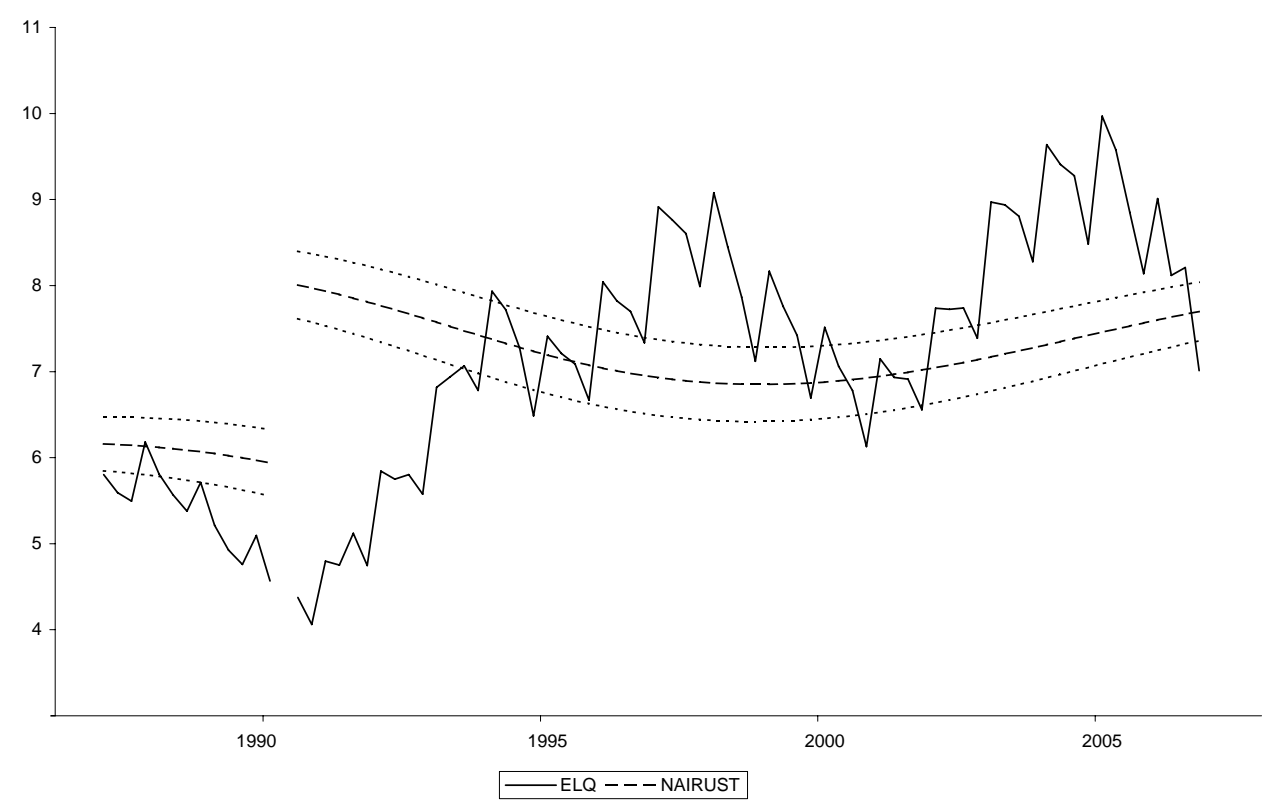


Model 7

Nairu plus $90 \%$ confidence bands - Partially linear model

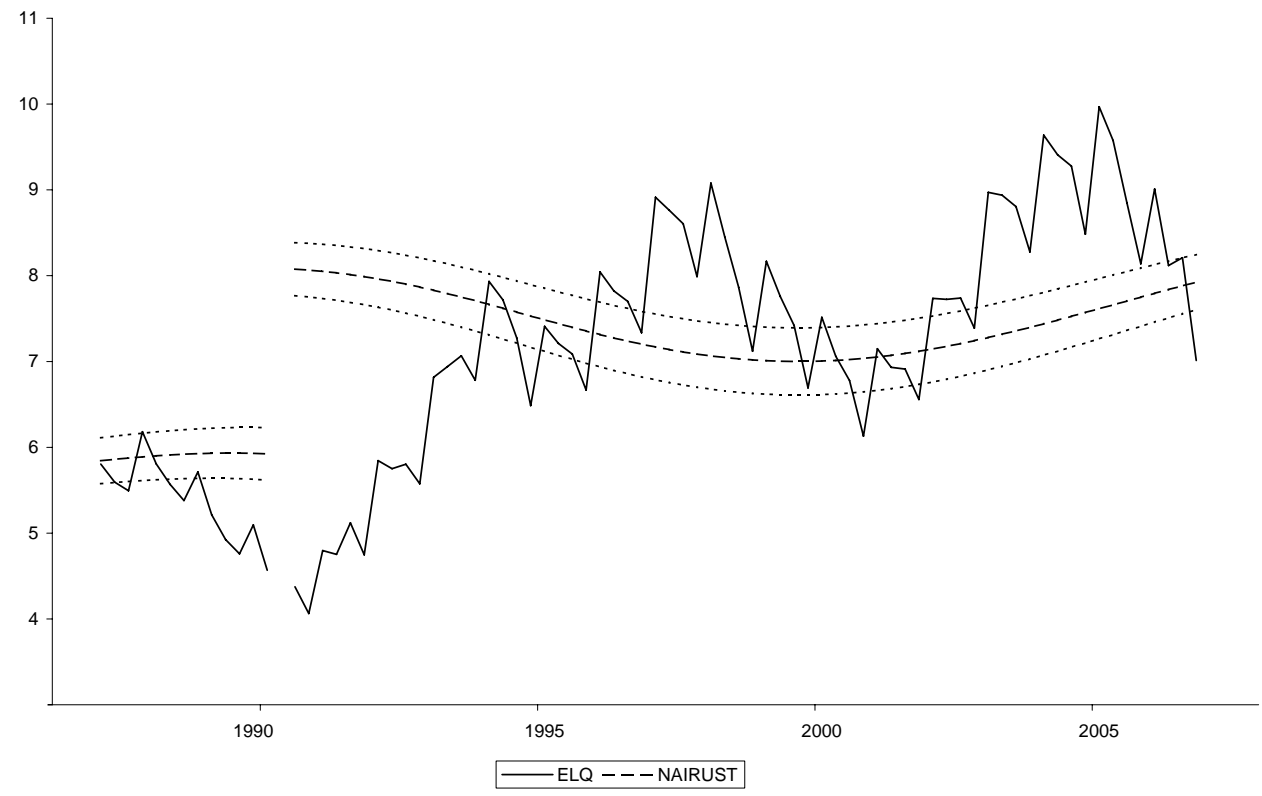

Model 8

Nairu plus $90 \%$ confidence bands - Partially linear model

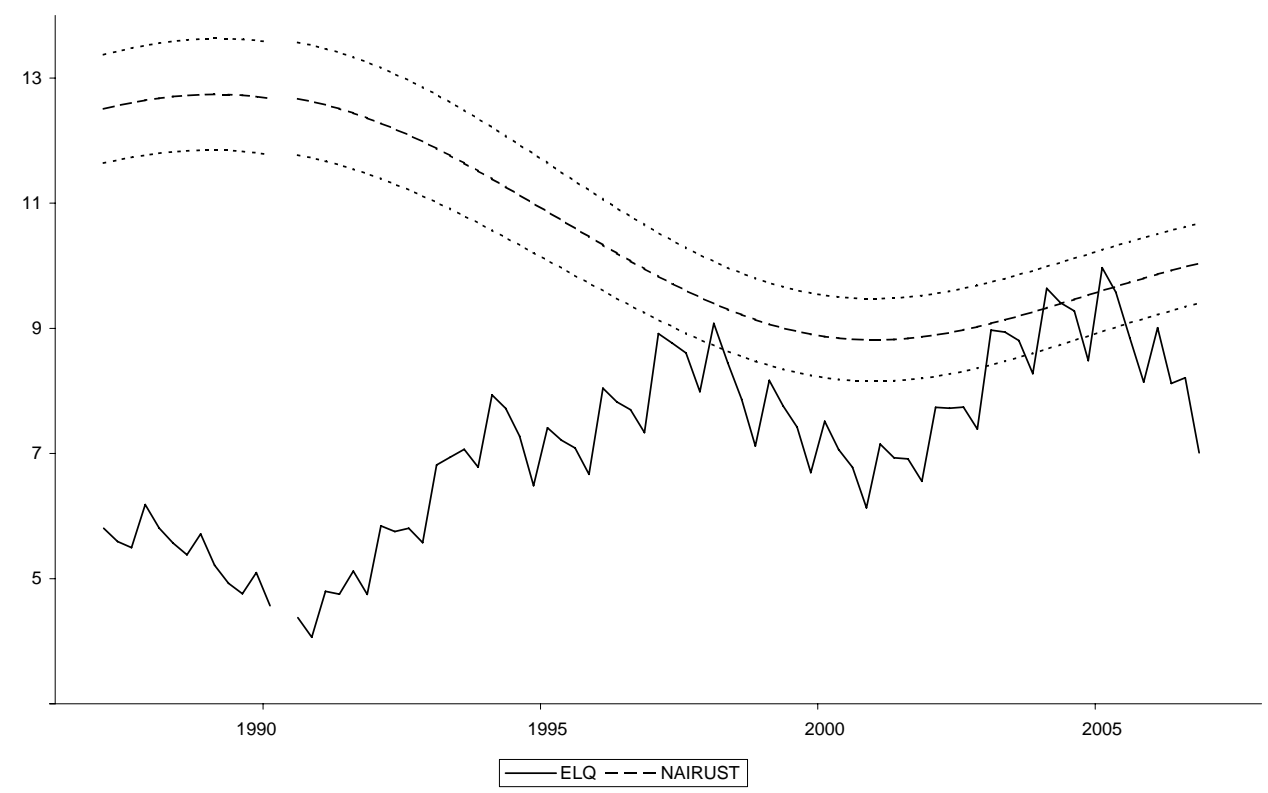




\section{Model 9}

Nairu plus 90\% confidence bands - Same Variance before/after Unification

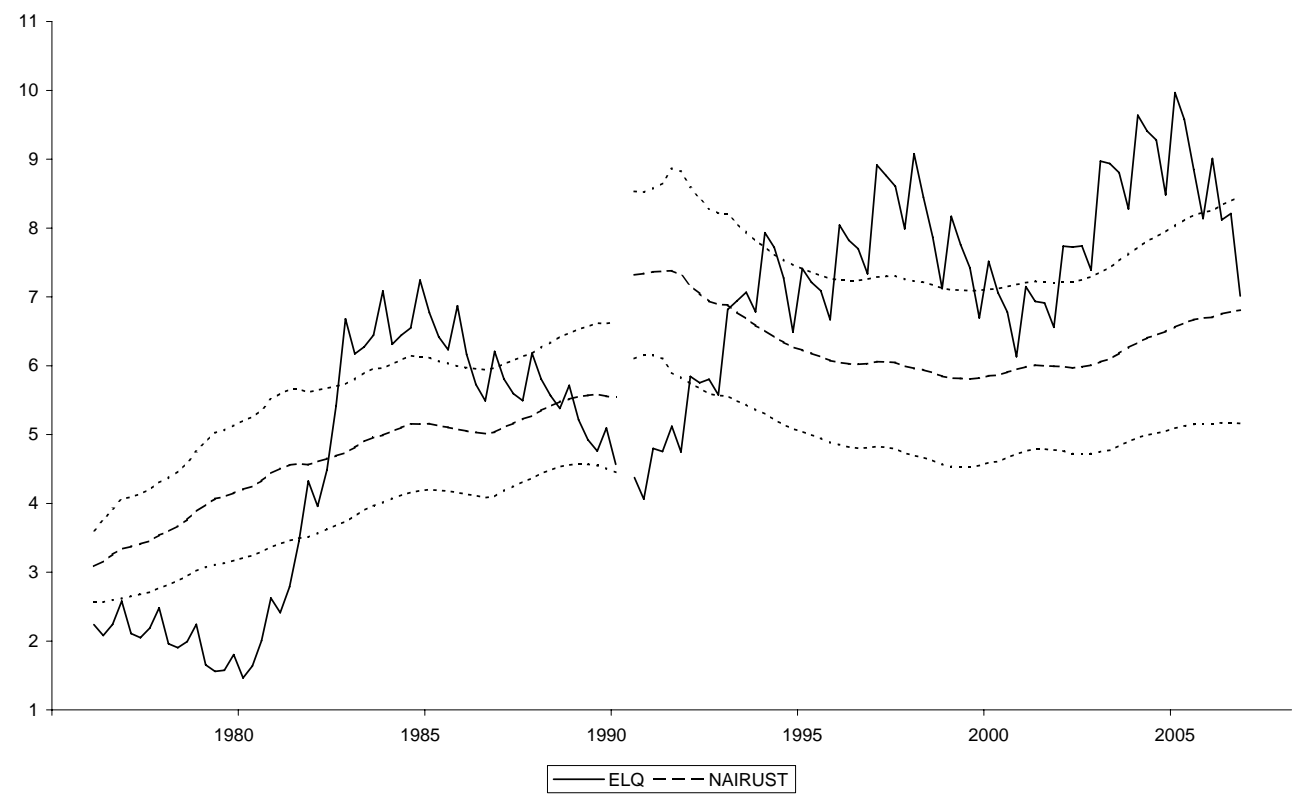

Nairu plus 90\% confidence bands - Different Variances before/after Unification

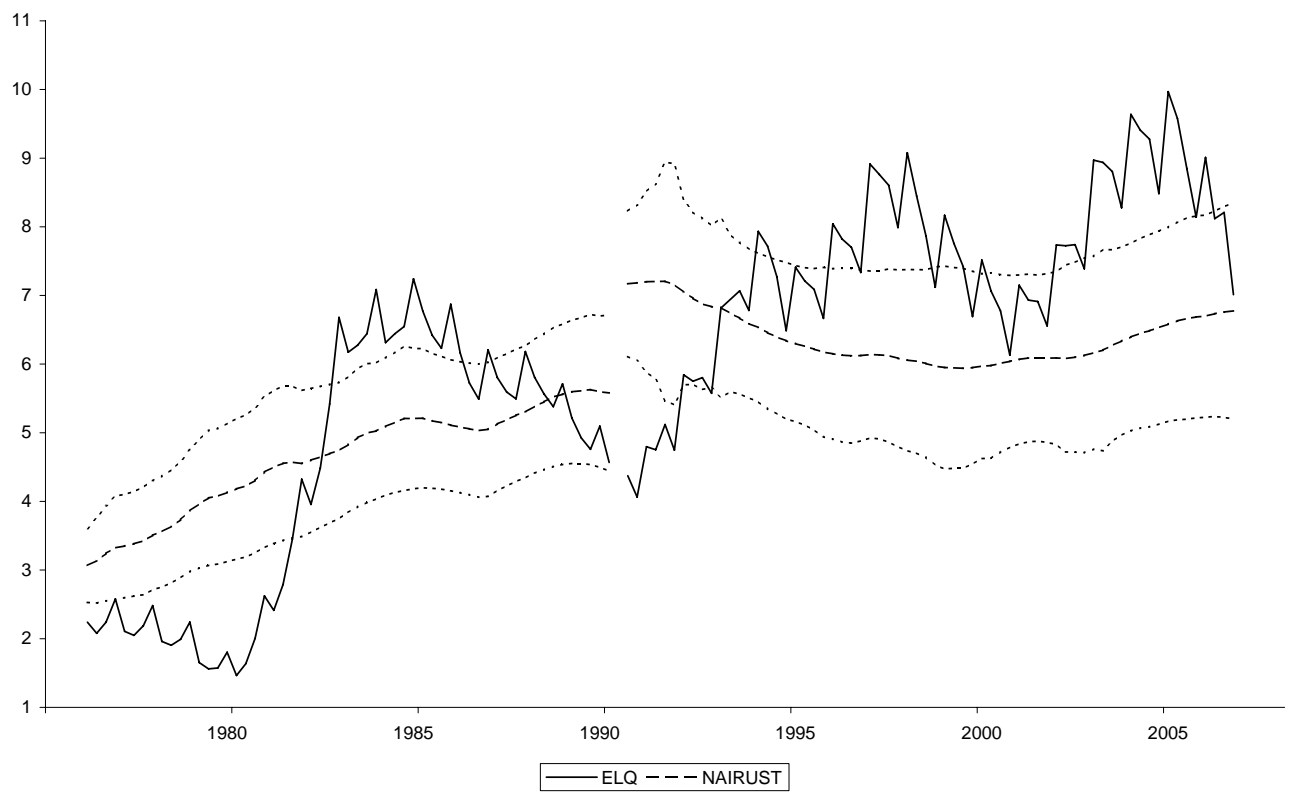


Nairu plus 90\% confidence bands - Partially linear model

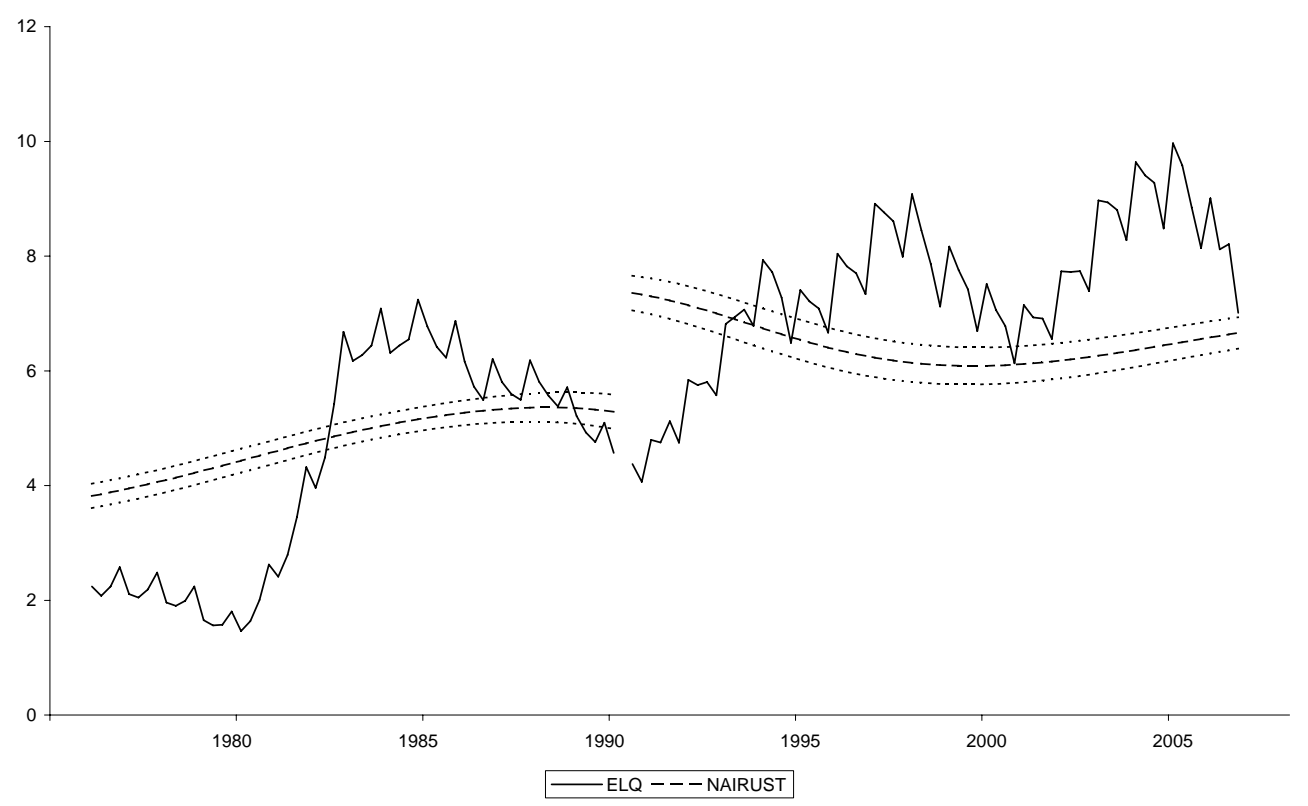

Model 10

Nairu plus 90\% confidence bands - OLS

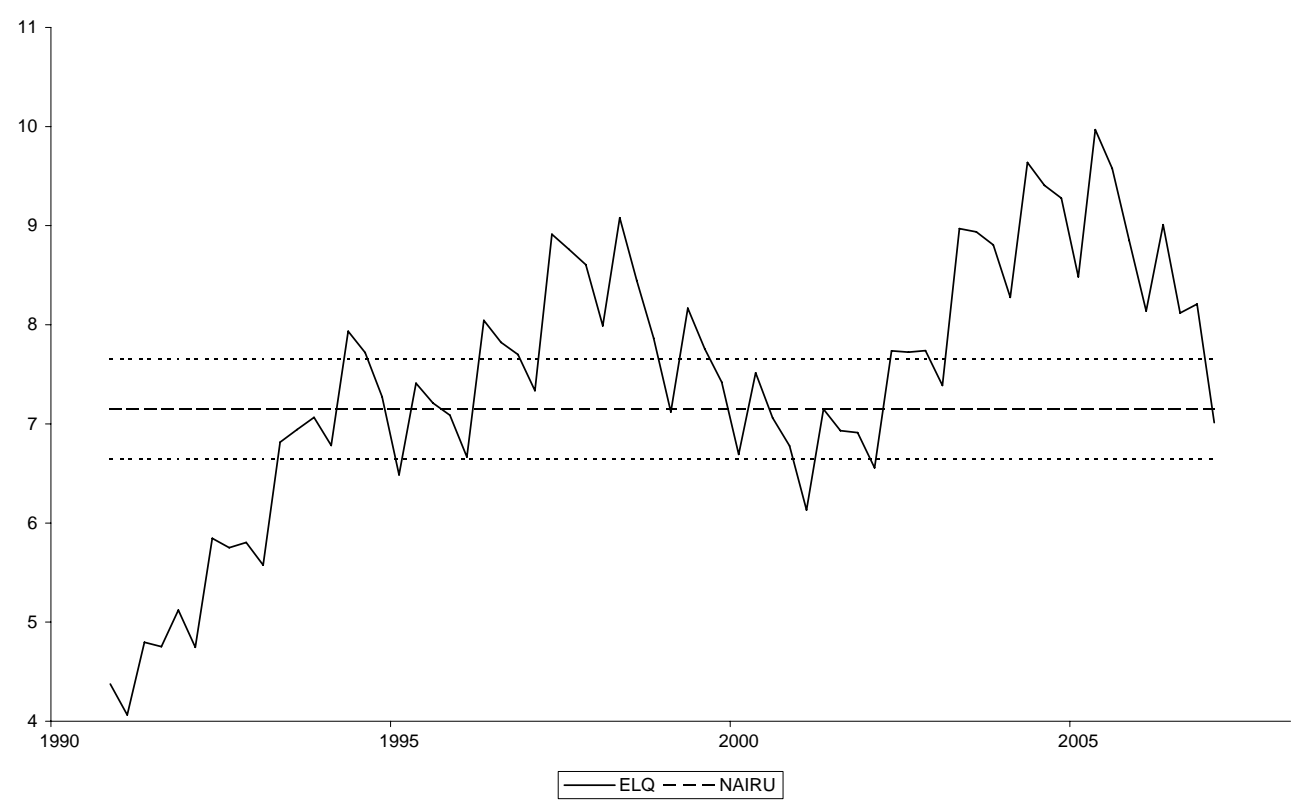

